\title{
Early Detection, Segmentation \& Quantification of Coronary Artery Blockage Using Efficient Image Processing Technique
}

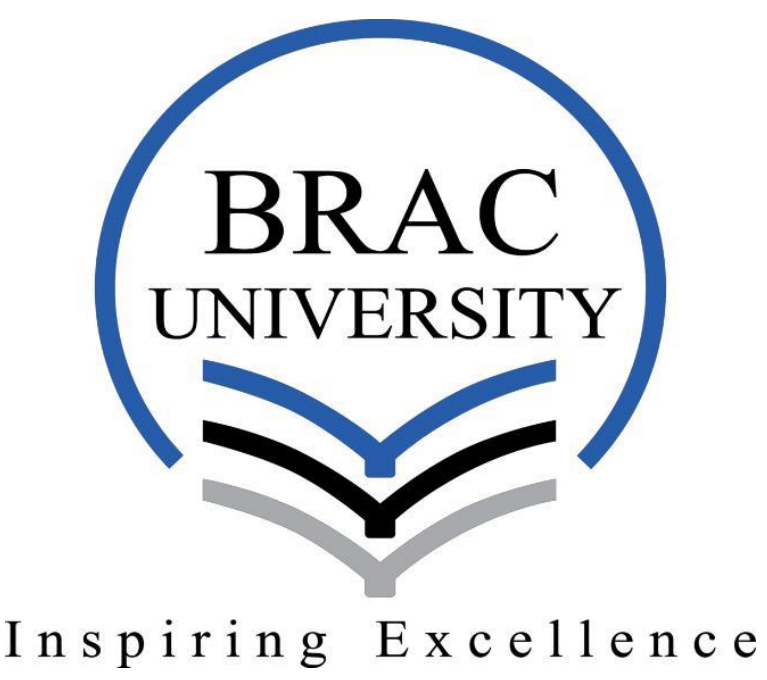

Department of Computer Science and Engineering School of Engineering and Computer Science BRAC University

Supervisor Dr. Md. Ashraful Alam

\author{
Mohsinul Bari Shakir - 13101068 \\ Mohammad Amzad Hossain - 13101016 \\ Khan Mohammad Aymaan Shams - 13101072 \\ Faisal Raihan Akib - 13101204
}




\section{DECLARATION}

We, hereby declare that this thesis is based on the results found by ourselves. Materials of work found by other researcher are mentioned by reference. This Thesis, neither in whole or in part, has been previously submitted for any degree.

\section{Supervisor}

Dr. Md. Ashraful Alam

Assistant Professor

BRAC University

Department of Computer Science \&

Engineering

ashraful.alam@bracu.ac.bd
Mohsinul Bari Shakir

13101068

shakir230895@gmail.com

\section{Authors}

Mohammad Amzad Hossain

13101016

amzad.ethan@gmail.com

Khan Mohammad Aymaan Shams

13101072

trimatrik.tz@gmail.com

Faisal Raihan Akib

13101214

akibmr9@gmail.com 


\section{Acknowledgements}

In the beginning, we would like to thank the almighty Allah for enabling us to conduct our research and allowing us to successfully conclude it.

Moreover, we would like to express our gratitude and appreciation to all those outstanding person who collaborated us throughout this research period. First of all, special thanks are due to Assistant Professor Dr. Md. Ashraful Alam, our thesis supervisor. He gave us invaluable advice, provided insight and helped us to implement this research work by providing helpful instructions about how to proceed with our work. In times of severe difficulties, he inspired us well and helped us to overcome the situation.

Last but not least, we are thankful to the faculties, seniors, friends and our beloved family who have motivated and inspired us throughout this journey. We should also appreciate all sorts of knowledge we could acquire from various resources from the internet from the work of fellow scholars and researchers. 


\begin{abstract}
Advancements in computing speed and power have made revolutionary changes in medical science practices and this is no different for cardiology. Such advancements in computer sciences have made the existing medical tests of heart into being. These tests are: ECG, CTA, \& Echocardiogram. CTA (Computed Tomography Angiography) is a widely used imaging technique to visualize arterial and venous vessels throughout the body. In clinical practice, the analysis mainly relies on visual inspection or manual measurements by experienced cardiologists. The proposed method aims towards a full automation of the detection of coronary artery blockage through some image processing techniques so that the system does not have to rely on any human's inspection. The goal of the research is to implement the proposed image processing techniques so that the system can detect the narrowing area of the wall of coronary arteries due to the condensation of different artery blocking agents. This detection is crucial for further analysis of the heart. The research suggests that the system will require a 64-slice CTA image as input. After the acquisition of the desired input image, it will go through several steps to determine the region of interest. This research proposes a two stage approach that includes the pre-processing stage and decision stage. The pre-processing stage involves common image processing strategies while the decision stage involves the extraction and calculation of two feature ratios to finally determine the intended result. In order to get more insights of the subject of these examinations, this research has proposed the use of an algorithm to create a 3-D model. Moreover, the system to work more precisely and effectively, use of several techniques have been suggested including parallel processing with shared memory allocation between the CPU and the GPU. Using the parallel processing technique not only makes the whole process at least 7 times faster, but also helps several stages of the process work more effectively.
\end{abstract}




\section{Contents}

Acknowledgements .......................................................... I

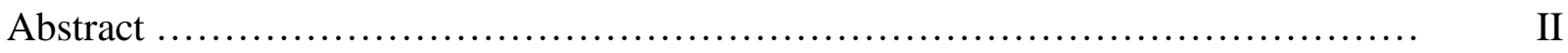

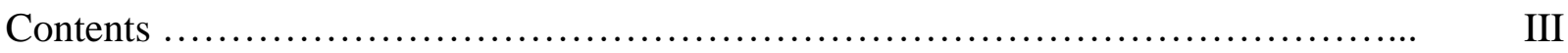

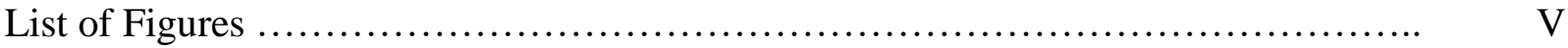

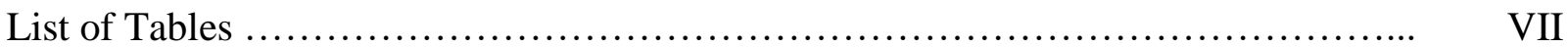

$\begin{array}{ll}\text { Chapter 1: Introduction } & 1\end{array}$

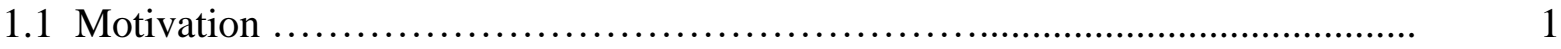

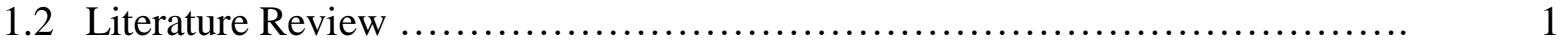

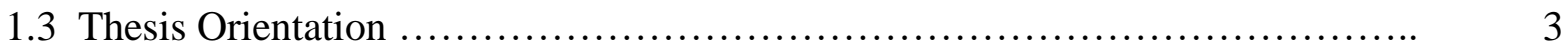

Chapter II: Fundamentals of Image Processing and Cardiovascular System 4

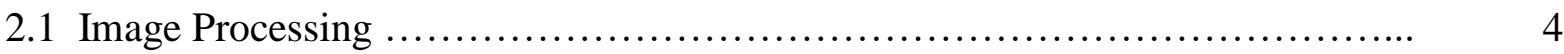

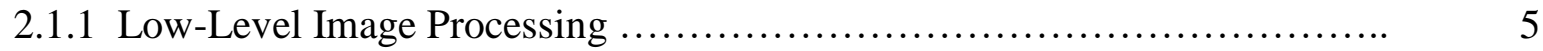

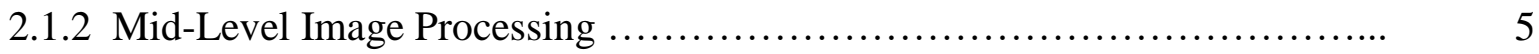

2.1.3 High-Level Image Processing ...................................... 6

2.2 Stages of Digital Image Processing ................................... 6

2.2.1 Image Acquisition ................................................ 7

2.2.2 Image Enhancement ........................................... 7

2.2.3 Image Restoration ............................................ 7

2.2.4 Morphological Processing ........................................... 8

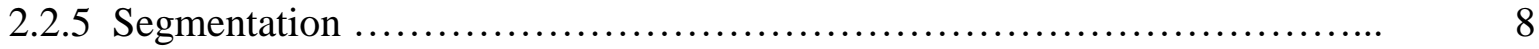

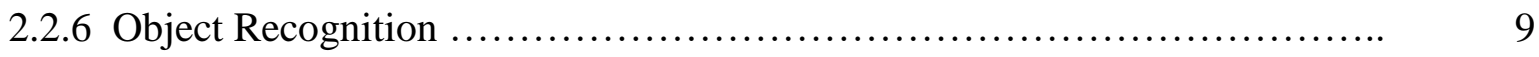

2.2.7 Representation and Description ................................... 9

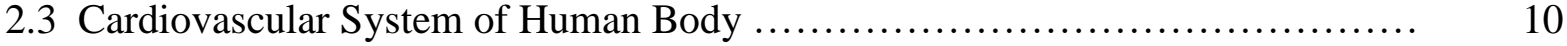

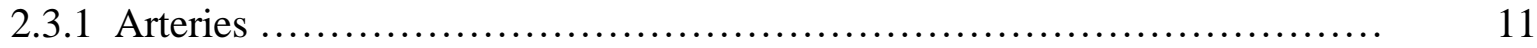

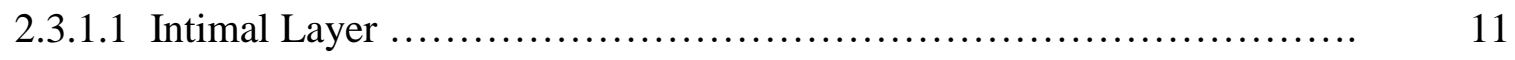

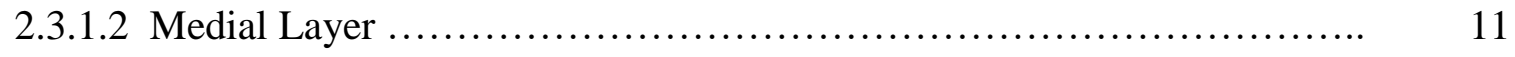

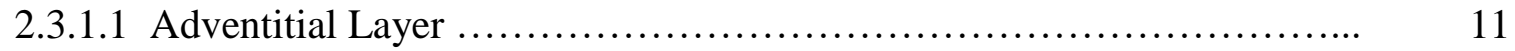

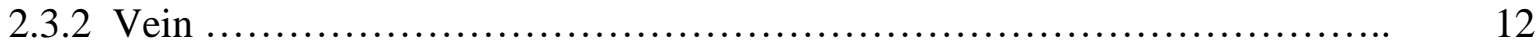

2.3.3 Capillaries ................................................... 12

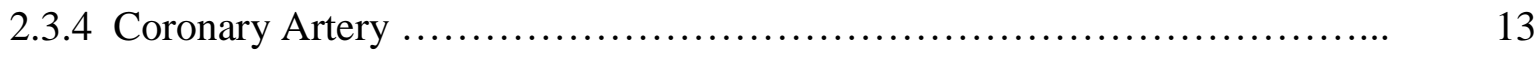


2.4 Image Processing Techniques for Coronary Artery Blockage Detection ......... 14

2.4.1 Median Filter .............................................................. 14

2.4.2 Gaussian Smoothing Filter ........................................ 15

2.4.3 OTSU's Threshold Algorithm ...................................... 16

2.4.4 Connected Components Labeling $\ldots \ldots \ldots \ldots \ldots \ldots \ldots \ldots \ldots \ldots \ldots \ldots \ldots \ldots \ldots$

2.4.5 Moore's Neighbor Tracing ........................................ 18

2.5 3D Visualization Techniques ...................................... 19

2.5.1 Ray Casting Technique ............................................ 19

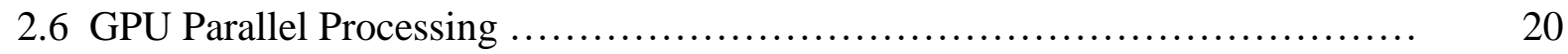

Chapter III: Proposed Method 23

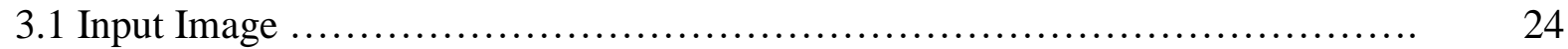

3.2 Image Scaling Using Nearest Neighbor Interpolation ...................... 25

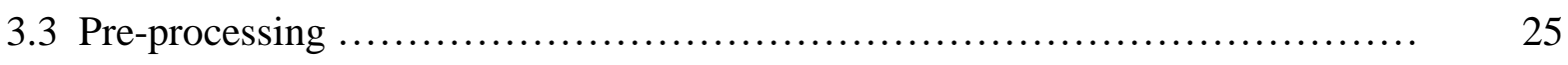

3.4 Segmentation of Coronary Artery ..................................... 27

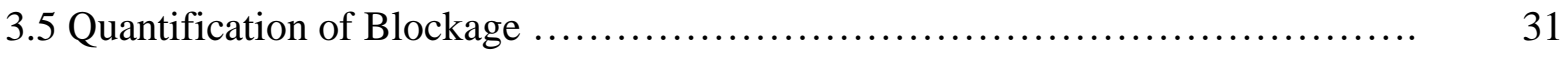

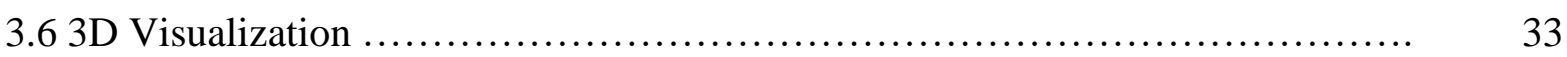

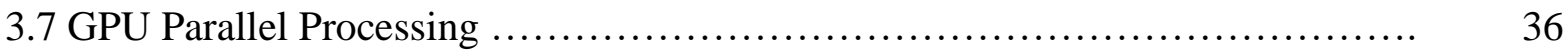

$\begin{array}{ll}\text { Chapter IV: Results } & 38\end{array}$

4.1 Simulation Methodologies......................................... 38

4.2 Identification of Degree of Stenosis ................................... 40

4.3 Accuracy of Otsu Threshholding Value................................ 42

4.5 Dataset of Perimeter Coordinates .................................... 43

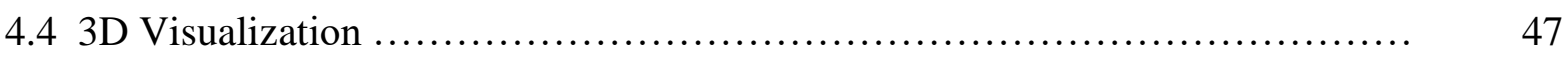

$\begin{array}{ll}\text { Chapter V: Conclusion } & 49\end{array}$

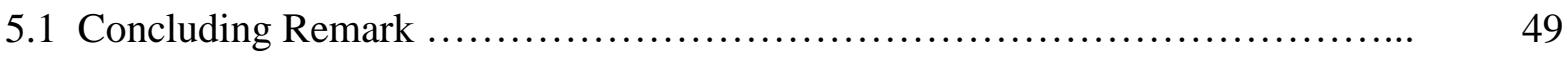

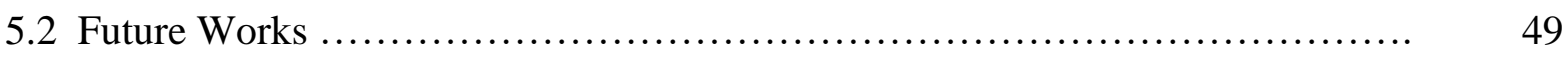

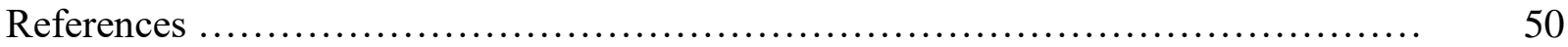




\section{List of Figures}

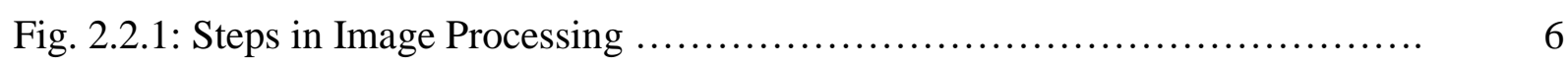

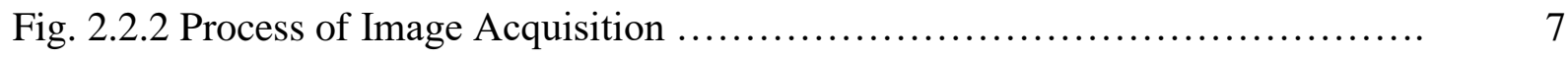

Fig. 2.3.1: Overview of Cardiovascular System .................................... $\quad 10$

Fig. 2.3.2: Demonstration of Arterial Layer ...................................... 11

Fig. 2.4.1 (a) Matrix of pixel (b) Median Filtered matrix of pixels .................... 14

Fig. 2.4.2 (a) Matrix of the image (b) Convolution Kernel .......................... 15

Fig. 2.4.3 Gaussian smoothing filtered matrix of the image .......................... 16

Fig. 2.5.1: Blinn/Kajiya model- A ray R cast into a scalar function of three spatial

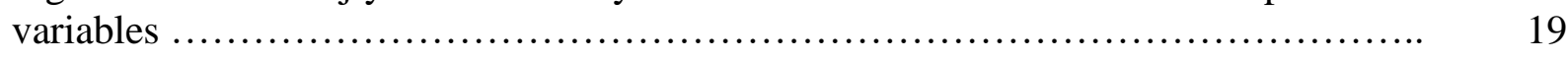

Fig. 3.1: Flowchart of the Proposed System .................................... 24

Fig. 3.1.1: (a,b) Two CTA image of 128 slices (c) CTA Image by Toshiba ............. 25

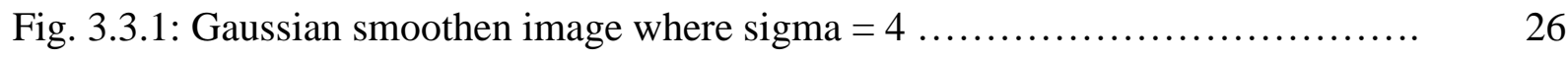

Fig. 3.3.2: Grayscale conversion using luminosity method ......................... 27

Fig 3.4.1: (a) Rejecting background from Toshiba CTA, (b, c) Rejecting background

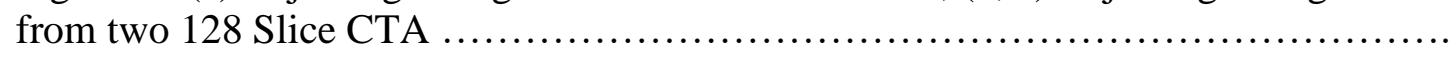

Fig. 3.4.2: (a) Segmented arteries from Toshiba CTA, (b, c) Segmented Artery from

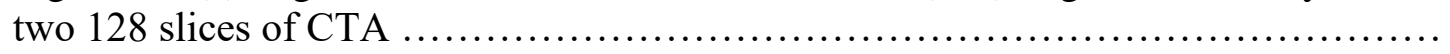

Fig. 3.4.3: Pixels Intensity of perimeters in green, (a) Toshiba CTA (b,c) two 128

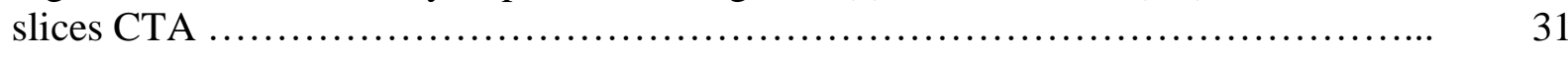

Fig. 3.6.1 Illustration of the "Additive Reprojection" method ......................... 34

Fig. 4.1.1: Illustration of the degree of Artery blockage .......................... 38

Fig. 4.1.2 Coronary Arteries (a) sample 1 (b) sample 2 (c) sample $3 \ldots \ldots \ldots \ldots \ldots \ldots \ldots . \quad 39$

Fig. 4.1.3: Detected Blockage in Sample 3 ...................................... 40

Fig. 4.2.1: Comparing the Percentages of Heart Blockage Using Specified Methods ... 
Fig. 4.2.2: Comparing the Percentages of Errors Using Specified Methods among the

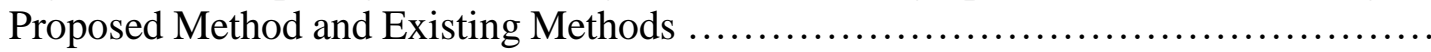

Fig. 4.3.1: Accuracy test result of Ostu Thresholding value ........................ 43

Fig. 4.4.1: Pixel Coordinates for Sample 1 ................................... 44

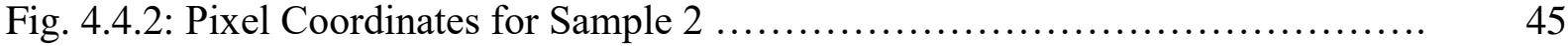

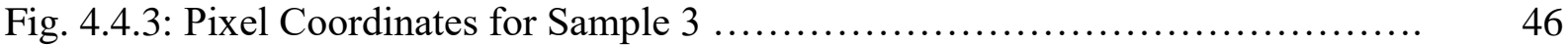

Fig. 4.5.1: 3D Model of Heart Using Volume Rendering ......................... 47

Fig. 4.5.2: 3D Model of Coronary Arteries Using Volume Rendering .............. 48 


\section{List of Tables}

Table 1: Comparison of Computation Times $\ldots \ldots \ldots \ldots \ldots \ldots \ldots \ldots \ldots \ldots \ldots \ldots \ldots \ldots \ldots \ldots \ldots \ldots \ldots \ldots$

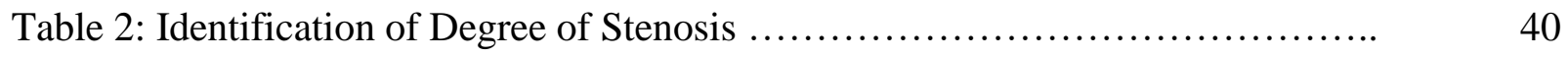

Table 3: Comparing the Percentages of Heart Blockage Using Specified Methods ... $\quad 41$

Table 4: Accuracy test result of Ostu Thresholding value ..................... 43 


\section{Chapter I}

\section{Introduction}

\subsection{Motivation}

The objective of this research study is early detection of the coronary artery blockage in various age groups for quick diagnosis. Nowadays, health care system enormously rely on medical image processing and digital image processing for extracting information about human body to diagnose almost all diseases. This paper proposes CTA (Computed Tomography Angiography) methods to extract relevant information for predicting coronary artery blockage. The challenge is to effectively diagnosis the images in order to extract information to understand the structure and function of the arteries being blocked. We believe, our proposed method will provide more accurate result in the way to detect Coronary Artery blockage as well as this will make the process simple than the more complex analysis of traditional Coronary CT angiography. We intend that after this research comes into physical being, dependency on human visual inspection will be highly minimized and more accurate diagnosis will be ensured.

\subsection{Literature Review}

Akhbardeh et al. presented categorization of the clogs in the arteries by applying the frames generated from the X-ray angiography. Performing image pre-processing methods includes selecting a line of Interest (on blocked artery and further selection of the region of interest on that area, then automatically cropping the region of interest followed by Gaussian filtering. The paper displayed three alternative methods are proposed to measure the stenosis in the vessel. The first method applies thresholding to extract the vessel of interest. The extracted vessel is analyzed for the calculation of the stenosis in percentage. The second method utilizes segmentation of the vessel tissue over the extracted pixels of ROI. The final method is based on using K-means clustering to differentiate between the vessel regions and non-vessel regions. Among the proposed methods Kmeans clustering based method outperforms better than others [1]. 
Supriya Agrawal in her paper proposes a method for automated segmentation of cardiac stenosis. Pre-processing is done for image analysis. Pre-processing includes image enhancement and pre-segmentation. Image enhancement is done to remove the noise removal and improves the visual quality. Segmentation of the arteries is done through Hessian based Frangi's vesselness filter. Abnormality in the segmented arteries is detected through Sobel Edge Gradient Operator along with the threshold values 76 to 80 . This projects the edges which are the regions having high spatial frequency. The gradient magnitude is computed at each point for detecting the stenosis [2].

Shahzad R. and et.al [3] in his work described a method which consists of extracting centerlines with the help of already known start and end points of arteries. Then it detects bifurcation points and then the points and centerlines are divided into segments. This changes centerlines to segments. The next step is to initialize the centerline segments for segmenting the lumen. The segmentation of the lumen is done by combining robust kernel regression and graphcuts.

Reiber J.H.C. and et all describes the methodology of such a computer-assisted analysis system, as well as the results from a validation study on the accuracy and precision. A region in a $35 \mathrm{~mm}$ cineframe encompassing a selected arterial segment is optically magnified and converted into video format by means of a specially constructed cinevideo converter and digitized for subsequent analysis by computer. Contours of the arterial segment are detected automatically on the basis of first and second derivative functions. Contour data are corrected for pincushion distortion; arterial dimensions are presented in $\mathrm{mm}$, where the calibration factor is derived from a computer-processed segment of the contrast catheter. The accuracy and precision of the edge detection procedure as assessed from cinefilms of perspex models (\%-D stenosis $\leqslant 70$ percent) filled with contrast agent were -30 and $90 \mu \mathrm{m}$, respectively. The variability of the analysis procedure by itself in terms of absolute arterial dimensions was less than $0.12 \mathrm{~mm}$, and in terms of percentage arterial narrowing for coronary obstructions less than 2.74 percent. It is concluded that this system allows the measurement of coronary arterial dimensions in an objective and highly reproducible way [4].

The geodesic active region model presented by Nikos and et all [23], who integrates boundary- based with region-based active contour approaches, is more effective than region-based snake segmentation methods, because prior knowledge about ROI is introduced. The important 
problems in the region-based approaches include the design of region- based models. We have used Vessel Enhancement Diffusion filtering developed by Frangi to enhance/Segment the vessels/Coronary arteries [5].

Mazinani M. and et all proposed an algorithm in their report on a similar kind of research. In order to extract coronary arteries and measure the degree of stenosis, they used Markovian fuzzy clustering method is applied to model uncertainty arises from partial volume effect problem. The algorithm employs: segmentation, centerline extraction, estimation of orthogonal plane to centerline, measurement of the degree of stenosis. To evaluate the accuracy, their approach has been applied to a vascular phantom and the results are compared with real diameter. [6]

\subsection{Thesis Orientation}

\section{The remaining part of this thesis paper is organized as follows:}

- Chapter 2 consists of discussion about the fundamentals of image processing and cardiovascular system in human body.

- Chapter 3 narrates the proposed model of our research.

- Chapter 4 explains the results found in our research.

- Chapter 5 wraps up this thesis with future research possibilities for out thesis. 


\section{Chapter II}

\section{Fundamentals of Image Processing and Cardiovascular System in Human Body}

\subsection{Image Processing}

The general idea of image processing refers to perform some operations or us an algorithm on a image and extract some information from that image to be used in future.

Image processing was first used in the early 1920s in a paper industry where images were coded for a submarine cable transfer \& reconstructed by a telegraph printer at the receiving point. In the mid to late 1920s, there had been improvements in the system. In 1964, image processing was used to improve the images of the moon taken by the Ranger 7 space probe. Such techniques were used in the other space missions as well. In the 1970s, image processing began to be used in the fields of medical science. In 1979, Allan M. Cormack and Godfrey N. Hounsfield jointly received The Nobel Prize for the invention of computer assisted tomography. Nowadays digital image processing is getting more and more attention because of the focus on two principal areas[24] which is given below -

- Improvements in the image information for human interpretation

- Processing of image for autonomous perception

Uses of image processing are expanding and now they are used in almost all areas.

Fields that use Image Processing:

- Medical Science

- Robot Vision

- Pattern Recognition

- Remote Sensing

- Restoration and Enhancements

- Digital Cinema 
- Transmission and Encoding

Visual representation of any two or three dimensional scene is called an image. To be precise,image is an array or a matrix where pixels (image elements) are arranged in a columns and rows.It can be considered as a two dimensional function $\mathrm{f}(\mathrm{x}, \mathrm{y})$ where $\mathrm{x}, \mathrm{y}$ are two spatial coordinatesthat represents the intensity or the gray level of the image at that point. Where there is image,image processing is involved. Image processing is one of the most widely used \&amp; rapidlygrowing technologies. It is the process of analyzing and manipulating a digitized image forquality enhancement or to extract any information from it.Image processing basically followsthese steps[25]:

- Importing image via image acquisition tools

- Analyzing and manipulation of image

- Output can be an image or report based on image analysis

Two types of methods are used for image processing named: Analogue and Digital Imageprocessing. Analogue image processing can be used for hard copies like printouts andphotographs since analogue are required for human viewing. Digital image processing involvesmanipulation of images in digitized way using a computer or other devices. There are threephases images go through for digital image processing[24]:

- Low-level image processing

- Mid-level image processing

- High-level image processing

\subsubsection{Low-Level Image Processing}

Main image processing phase where noise-reduction, image-sharpening, enhancement etc operations are performed.

\subsubsection{Mid-Level Image Processing}

Image analysis phase where segmentation and classification of image operation is carried out. 


\subsubsection{High-Level Image Processing}

The final phase where we can visualize the output image by assembling the recognized objects.

\subsection{Stages of Digital Image Processing}

Image processing is a series of process and the output is acquired by step by step execution of several operations. Some core stages that is common is all sort of image processing are stated below -

1. Image Acquisition

2. Image Enhancement

3. Color Image Processing (Optional for B\&W pictures)

4. Image Restoration

5. Image Compression

6. Morphological Processing

7. Image Segmentation

8. Representation \& Description

9. Classification \& Object Recognition

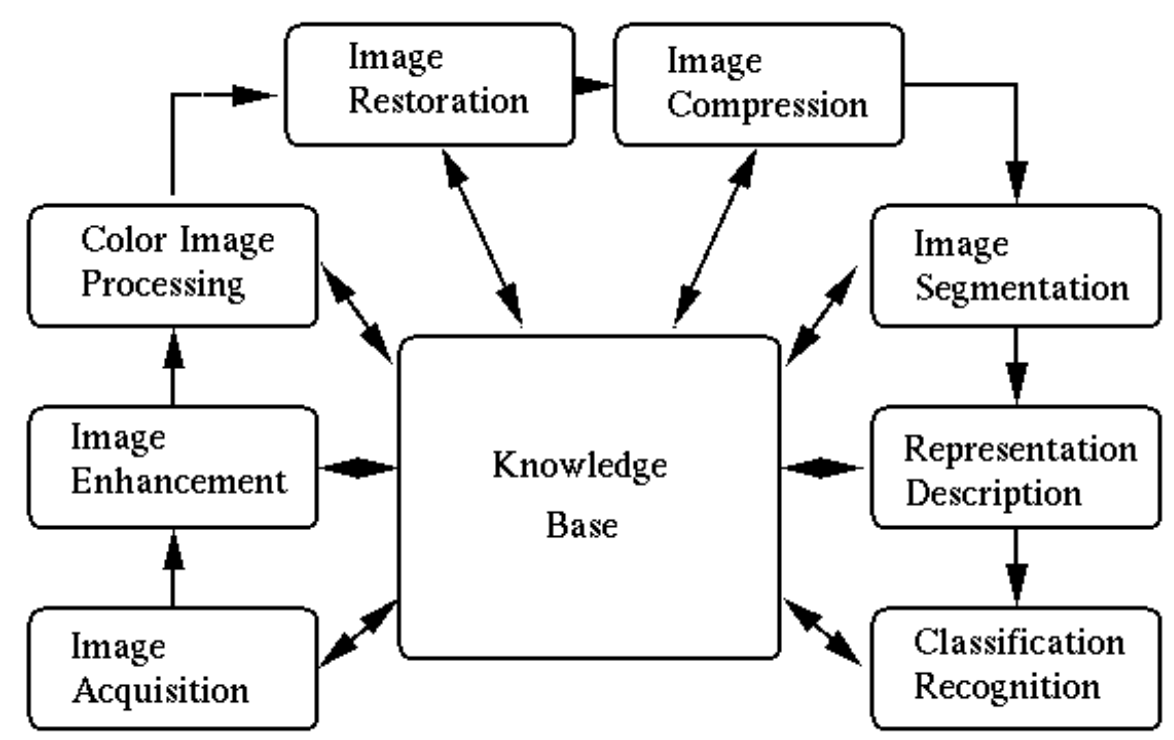

Fig. 2.2.1: Steps in Image Processing 


\subsubsection{Image Acquisition}

Image acquisition is the first stage in image processing. An image can be achieved in several ways or could be already in a digital form to be used for various image processing operation. An image is generated from a combination of illuminated source. Depending on whether the light is being reflected or absorbed by the elements of that source, the image is created accordingly. Digital images are formed by transformation of illumination sources by imaging sensors[25].

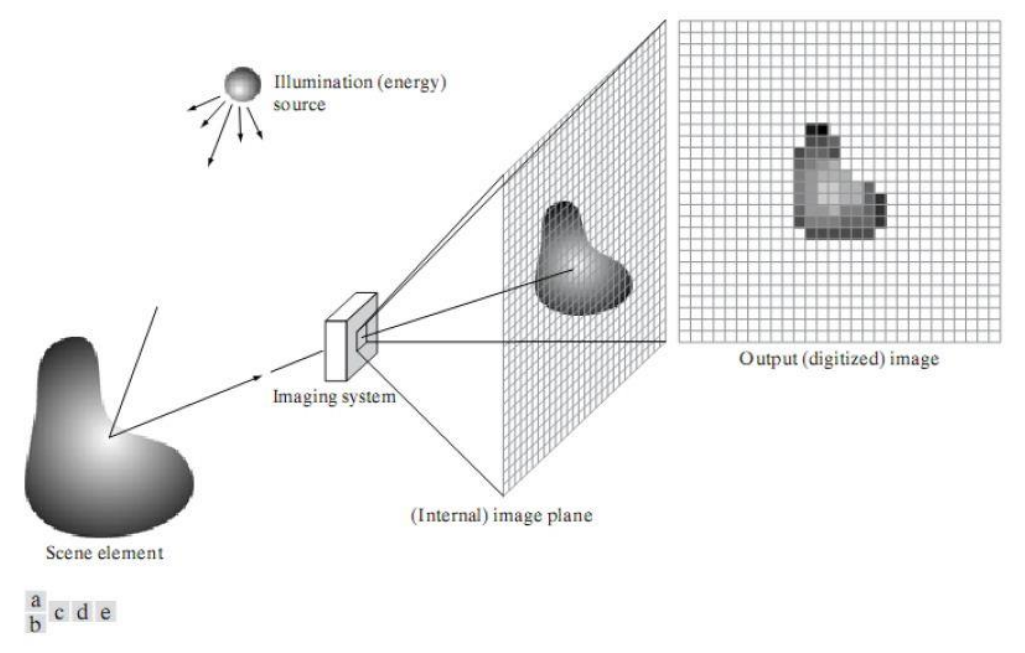

Fig. 2.2.2: Process of Image Acquisition.

Image acquisition refers to the pre-processing stage, such as scaling [1].

\subsubsection{Image Enhancement}

The primary goal of image enhancement is to have the improved visual quality of image. Image enhancement sharpens image attributes like the edges, boundaries and contrast to make the image more suitable for analysis and visualization. This technique can increase the dynamic range of specific attributes in order for better analysis.

\subsubsection{Image Restoration}

Image restoration technique is applied to increase the quality of an image based on the information of the physical process by which it was formed [39]. This technique uses the 
degradation information and according to the information inverse process is applied. A simple formula of the image restoration is:

$$
y(i, j)=H[f(i, j)]+n(i, j)
$$

Here, $y(i, j)$ is the degraded image, $f(i, j)$ is the original image, $\mathrm{H}$ is the operator for degradation process and $n(i, j)$ is the external noise.

\subsubsection{Morphological Processing}

One of the main approach of this research work is to differentiate the target area from a CTA image report. However, the identification of any object from an image can be a very tricky business, if proper methodologies are not followed. In order to get the task done, morphological processing of an image processing technique and is one of the globally accepted primary approaches that simplifies the image by changing the grayscale image into a binary one.

Binary image is an image in which the value of each pixel is restricted to either 1 or 0 . The foundation of this operation lies in the mathematically rigorous field of set theory. However, that level of sophistication will be hardly needed in this research. Usually, while executing operations like morphological image processing, as has happened in this research, a solution needs to be developed through trial-and-error basis.

\subsubsection{Segmentation:}

In the field of image processing, new technologies are being introduced and this is no different in the segmentation sector. Segmentation basically implies to the process of dividing the source image into smaller, more meaningful segments so that the target area can be identified more easily in the future processing.

Segmentation can be classified into the following types [41]:

- Region based

- Edge based

- Threshold 
- Feature based clustering and

- Model based

Segmentation accuracy determines the eventual success of the computational analysis.

\subsubsection{Object Recognition}

The object recognition stage comes after morphological processing and segmentation in terms of serial and considered as the last step in the digital image processing. Like human understanding, it includes:

- Detection

- Description

- Classification

- Identification and

- Understanding

In this research, this step identifies the target area which is used in the next step to determine the final result. The methods have been selected by trial-and-error approach.

\subsubsection{Representation \& Description}

Representation and description always follows the output data from segmentation stage, which is raw pixel data.

\section{Representation:}

Boundary representation is valid when focus is on external shape characteristics such as corners. Regional representation is appropriate when the focus is on internal properties, such as texture.

\section{Description:}

It is also known as feature selection, deals with extracting attributes that results in some quantitative information of interest or are basic for differentiating one class from another. 


\subsection{Cardiovascular System of human Body}

The circulatory system, which is also known as cardiovascular system or the vascular system, is generally an internal organ system in human body which enables blood to circulate and travel around the human body through blood vessels. There are three main types of blood vessel in human body -

- Arteries

- Vein

- Capillaries

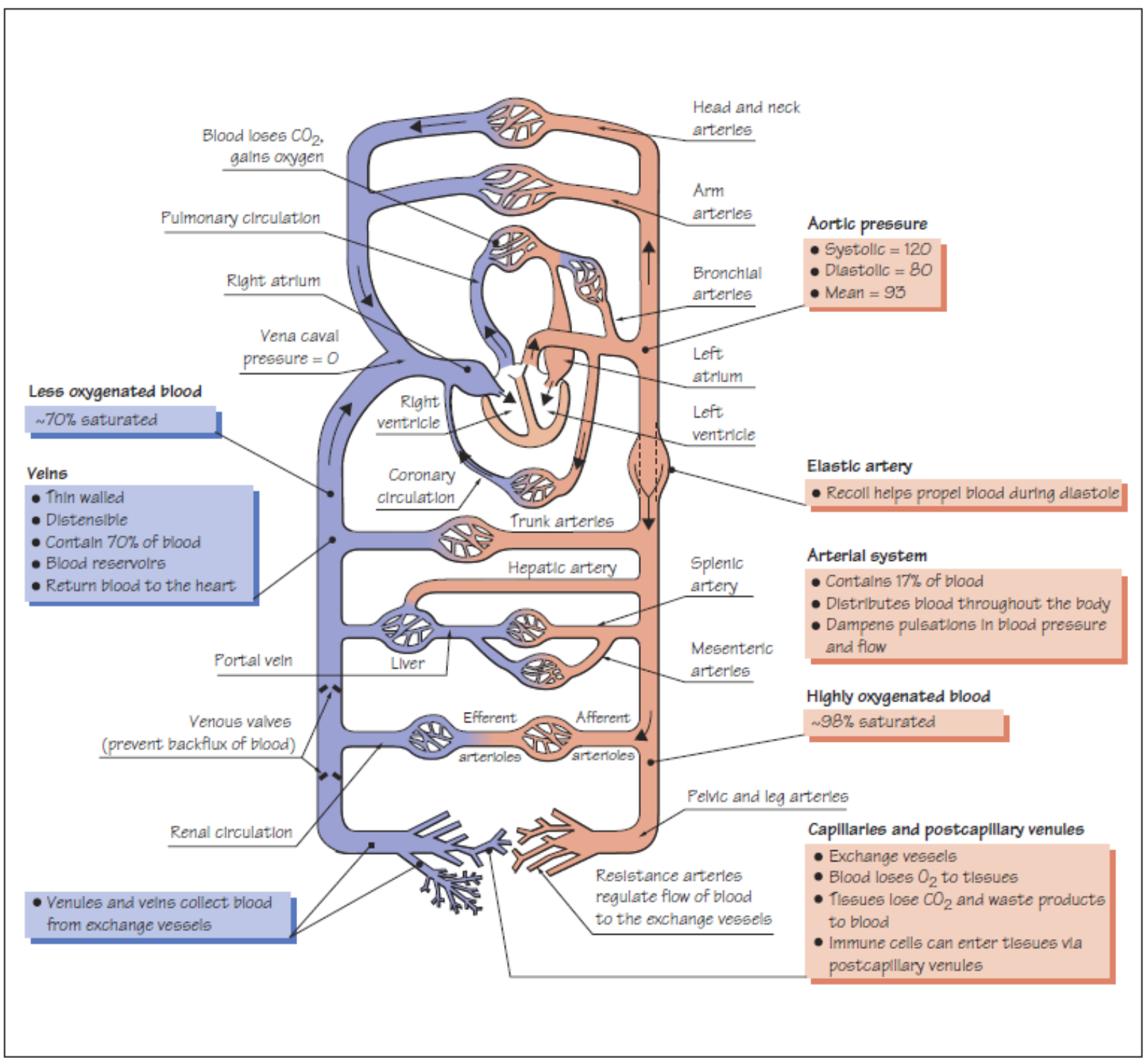

Fig. 2.3.1: Overview of Cardiovascular System. 


\subsubsection{Arteries}

The arteries in human cardiovascular system are specified as the blood vessels which deliver oxygen-rich blood pumped from the heart to each organ of the body independently. Every artery is generally tube made from muscles and lined by smooth tissues.Arteries have three layers in it[26]:

- The Intimal Layer.

- The Medial Layer.

- The Adventitial Layer.

\subsubsection{Intimal Layer}

The inner layer of an artery which is lined by a smooth tissue known as endothelium

\subsubsection{Medial Layer}

A layer of muscle inside the artery which enable the arteries to handle the high blood pressures of travelling blood from the heart.

\subsubsection{Adventitial Layer}

Denotes as connective tissues within anchoring arteries to another artery of nearby location.

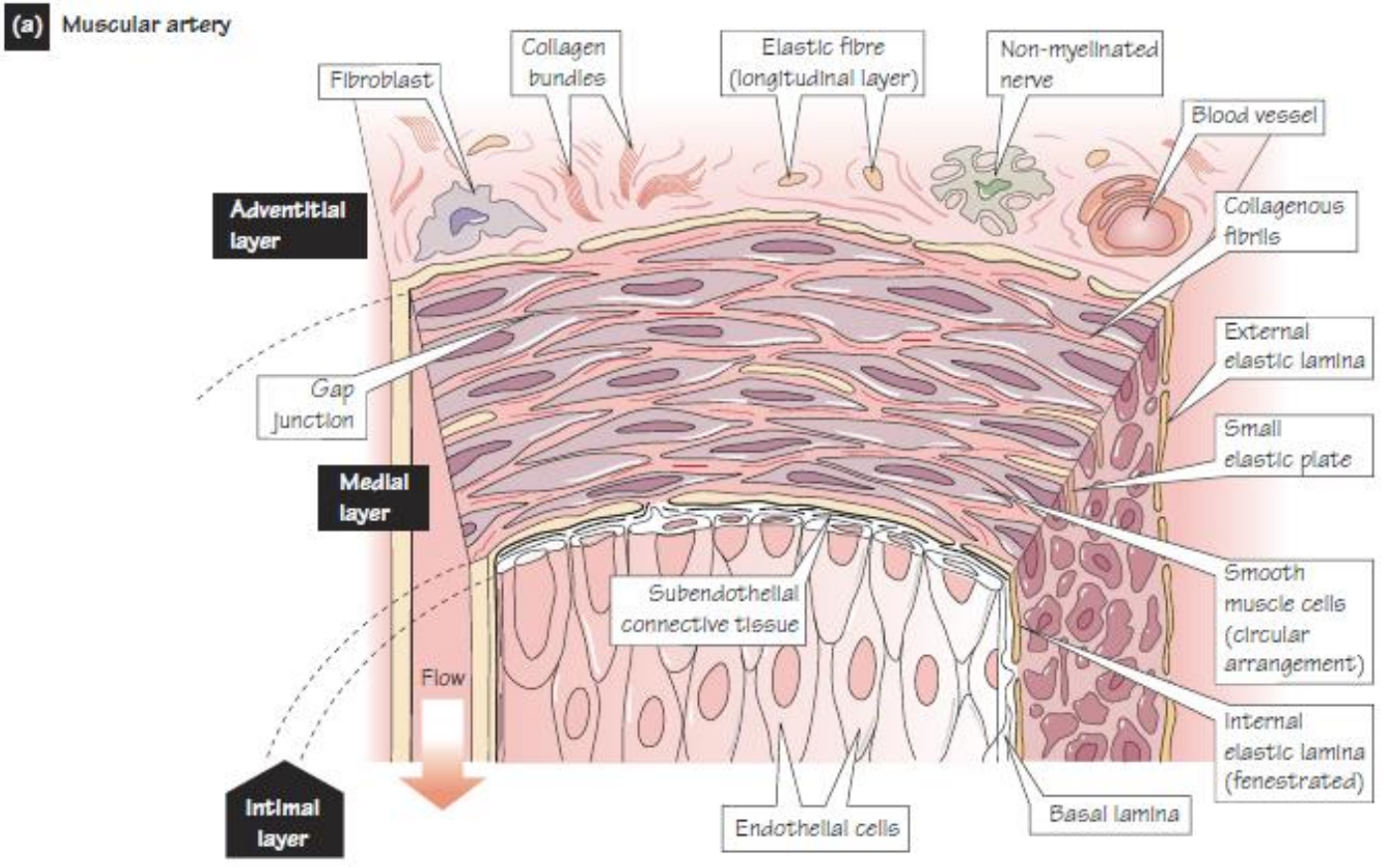

Fig. 2.3.2: Demonstration of Arterial Layer 
The largest artery in human cardiovascular system in know as Aorta. This is the connected to the heart's left ventricle and is the main high pressure pipeline. The aorta is divided into a series of smaller arteries and spread in network throughout the human body. Small branches of the arteries are names as arterioles and capillaries. There is an artery with a unique and special functionality of carrying oxygen-poor from the heart to lungs under low pressure situation is called The Pulmonary Arteries. The additional purpose of arteries is to transport nutritional elements such as oxygen, carbon dioxide, amino acids, electrolytes, hormones etc to the body[26].

\subsubsection{Vein}

In human cardiovascular system, veins play a vital role. After arteries carry the blood out of the heart, it is the responsibility of the veins to return deoxygenated blood back to the heart. The venous system consists of two parts[26] -

- Venules, this is formed by one or two layers or smooth muscle cells.

- The Veins.

In order to prevent the blood flow to the backward direction, paired semilunar valves are present in the veins of the limb, especially the legs. The largest vein in the human body is known as Vena Cava which has two parts-

- Superior Vena Cava, contains veins from from upper body (head, neck \& arms).

- Inferior Vena Cava, contains veins from the lower body.

Both superior and inferior vena cava deliver blood to the right atrium. From there blood is pumped into the right ventricle. The artery supplying oxygen-rich blood to a region and one or two veins draining deoxygenated blood from that region generally placed next to each other[26].

\subsubsection{Capillaries}

Capillaries are the smallest type of blood vessels in human cardiovascular system which is responsible for enabling the exchange of substances between the blood and surrounding tissues. Capillaries are made of thin walls and consists no smooth muscles. This thin wall eases the 
exchange of substances. The wall of capillary are composed of Lumen (The space inside a tubular structure for blood to flow) and Endothelium[5]. Capillaries are of two types[27] -

- Continuous Capillary

- Fenestrated Capillary

- Sinusoids

\section{Continuous Capillary}

This is most important for brain and forms some part of the blood brain barrier. Also, it enables the diffusion of water, soluble materials in lipid and small molecules into the surrounding tissue fluid. Continuous Capillary retains the amount of red blood cell and plasma proteins[27].

\section{Fenestrated Capillary}

Enable a fast exchange of water and comparatively large solutes between plasma and interstitial fluid[27].

\section{Sinusoids}

Enable a free exchange of water and even larger solutes between blood and interstitial fluid

\subsubsection{Coronary Artery}

Heart is formed with cardiac muscles the continuously contracts and relaxes. All tissues in human body oxygen-rich blood to function properly and heart muscles are no different. Coronary Arteries are a network of oxygen and nutrient rich blood. They supply oxygen rich blood to the heart muscle. The coronaries can seen as wrapping around the heart from outside and small brunches enter the heart from the surface to supply blood. There are two types of coronary arteries[40]-

\section{Left main Coronary Artery:}

- Supplies blood to the left ventricle and left atrium which is the left side of the heart muscle.

\section{Right main Coronary Artery:}

- Supplies blood to the right ventricle and right atrium which is the right side of the heart muscle. 
The left and right coronary arteries emerge from the near top of heart. Aorta, which is the main artery of human body is the starting of both coronary arteries. Due to being responsible for the transportation of oxygen and nutrients to the heart as well the body, coronary arteries are very important. Any malfunction or blockage in coronary arteries can seriously damage the heart and can be fatal for human life.

\subsection{Image Processing Techniques Related to Coronary Artery Blockage Detection}

\subsubsection{Median Filter}

Median filter is also used to reduce the amount of noise in an image. But it has two major advantages over mean filter. Firstly is gives more vigorous average of the pixels than mean filter. Secondly, it does not create unrealistic pixel value while filtering. Thus gives us sharper edges than mean filtered image [21]. Median filter also follows a simple working procedure. For every pixel in an image, its neighbor pixels are considered. First the neighboring pixels are sorted out and then the pixel is replaced by the median value of all the sorted pixels and if the neighboring pixels are even in number, then the average value of the middle two pixel value is used for the replacement [22]. An illustration of the calculation of median filtering is given below.

\begin{tabular}{|c|c|c|}
\hline 6 & 4 & 2 \\
\hline 7 & 12 & 9 \\
\hline 3 & 5 & 8 \\
\hline
\end{tabular}

(a)

\begin{tabular}{|c|c|c|}
\hline 6 & 4 & 2 \\
\hline 7 & 6 & 9 \\
\hline 3 & 5 & 8 \\
\hline
\end{tabular}

(b)

Fig. 2.4.1 (a) Matrix of pixel (b) Median Filtered matrix of pixels

Here, the center pixel value is 12 . If the neighboring pixels are being sorted, then the sorted list will be as: $2,3,4,5,6,7,8,9$, and 12 . The median value of the list is 6 . Hence the center value 
(previously 12) will be replaced by 6.

\subsubsection{Gaussian Smoothing Filter}

The Gaussian smoothing operator is a 2-D convolution operator that uses a Gaussian function for calculating the transformation in each pixel. It is widely used to 'blur' images and also for removing noises and details from an image. The equations of Gaussian function in both 1D and 2D are given below:

$$
\begin{aligned}
& G(x)=\frac{1}{\sqrt{2 \pi \sigma^{2}}} e^{-\frac{x^{2}}{2 \sigma^{2}}} \\
& G(x)=\frac{1}{2 \pi \sigma^{2}} e^{-\frac{x^{2}+y^{2}}{2 \sigma^{2}}}
\end{aligned}
$$

Here $x$ is the distance from the origin in the horizontal axis, $y$ is the distance from the origin in the vertical axis, and $\sigma$ is the standard deviation of the Gaussian distribution.

Gaussian smoothing uses 2-D distribution function and when calculating new values of a given pixel, convolution operator id being used. Convolution takes values of the neighboring pixels into account. The main element of a convolution is kernel which is a matrix of arbitrary size mostly a square matrix. When calculating the new value of the selected pixel, the convolution kernel is applied to it by its center pixel. Neighboring pixels are covered with the same kernel. Next, the sum of the product of the pixels is calculated in the image. The resulting sum is the new value of the selected pixel. Now, if the convolution is applied to each pixel in the image, we get a certain effect, which depends on the chosen convolution kernel. An example of the calculation of Gaussian Smoothing is given below.

\begin{tabular}{|l|l|l|}
\hline 47 & 48 & 49 \\
\hline 47 & 50 & 42 \\
\hline 47 & 48 & 42 \\
\hline
\end{tabular}

(a)

\begin{tabular}{|l|l|l|}
\hline 0 & 1 & 0 \\
\hline 0 & 0 & 0 \\
\hline 0 & 0 & 0 \\
\hline
\end{tabular}

(b)

Fig. 2.4.2 (a) Matrix of the image (b) Convolution Kernel 
The result is calculated in following way:

$\operatorname{Result}=\left(47^{\star} 0\right)+\left(48^{\star} 1\right)+\left(49^{*} 0\right)+\left(47^{\star} 0\right)+\left(50^{\star} 0\right)+\left(42^{\star} 0\right)+\left(47^{\star} 0\right)+\left(48^{\star} 0\right)+\left(42^{*} 0\right)=48$

The result of applying kernel to a pixel with center value of 50 will be:

\begin{tabular}{|c|c|c|}
\hline 47 & 48 & 49 \\
\hline 47 & 48 & 42 \\
\hline 47 & 48 & 42 \\
\hline
\end{tabular}

Fig. 2.4.3 Gaussian smoothing filtered matrix of the image

\subsubsection{OTSU's Threshold Algorithm}

OTSU's algorithm is an image binarization algorithm named after its inventor Nobuyuki Otsu. This algorithm assumes that an image has two types of pixels (foreground pixels and background pixels), it then calculates the optimum threshold separating the two classes so that their combined spread is minimal, or equivalent, so that their inter-class variance is maximal [29]. In this method, a threshold value is searched that minimizes intra-class variance, defined as a weighted sum of variances of the two classes:

$$
\sigma_{\omega}^{2}(t)=\omega_{0}(t){\sigma_{0}}^{2}(t)+\omega 1(t) \omega_{1}^{2}(t)
$$

Weights $\omega_{\boldsymbol{0}}$ and $\omega_{\boldsymbol{1}}$ are the probabilities of the two classes separated by a threshold $\boldsymbol{t}$ and $\boldsymbol{\sigma}_{0}^{2}$ and $\boldsymbol{\sigma}_{1}{ }^{2}$ are variances of these two classes. The class probability $\omega_{0,1}(t)$ is computed from the $\boldsymbol{L}$ bins of the histogram:

$$
\begin{gathered}
\omega_{0}(t)=\sum_{i=0}^{t-1} p(i) \\
\omega_{1}(t)=\sum_{i=t}^{L-1} p(i)
\end{gathered}
$$

Otsu shows minimizing the intra-class variance and maximizing inter-class variance is equivalent.

$$
\begin{gathered}
\sigma_{b}^{2}(t)=\sigma^{2}-\sigma_{\omega}^{2}(t) \\
=\omega_{0}\left(\mu_{0}-\mu_{T}\right)^{2}+\omega_{1}\left(\mu_{1}-\mu_{T}\right)^{2} \\
=\omega_{0}(t) \omega_{1}(t)\left[\mu_{0}(t)-\mu_{1}(t)\right]^{2}
\end{gathered}
$$


This is expressed in terms of class probabilities $\boldsymbol{w}$ and class means $\boldsymbol{\mu}$, while the class mean $\boldsymbol{\mu}_{10,1, T}(t)$ is:

$$
\begin{aligned}
& \mu_{0}(t)=\sum_{i=0}^{t-1} i \frac{p(i)}{\omega_{0}} \\
& \mu_{1}(t)=\sum_{i=t}^{L-1} i \frac{p(i)}{\omega_{1}} \\
& \mu_{T}=\sum_{i=0}^{L-1} i p(i)
\end{aligned}
$$

In Matlab, we used the built-in function graythresh() which is implemented with Otsu's algorithm.

\subsubsection{Connected Components Labeling}

Connected components labeling detects connected regions by scanning an image based on pixel connectivity. Pixels in connected components have some pixel intensity values in common and they are someway connected with one another. After determining the connected regions, all the pixels are labeled with a color. Connected components labeling scans an image from top to bottom and from left to right, pixel by pixel for identifying connected pixel group for example regions of adjacent pixels which share the same set of intensity values. The connected components labeling operator scans the image by moving along a row up to a point $p$ (where $p$ denotes the pixel to be labeled at any stage in the scanning process) for which $V=\{1\}$. When this is true, it examines the four neighbors of $p$ which have already been encountered in the scan.

Based on this information, the labeling of $p$ occurs as follows:

- If all four neighbors are 0 , assign a new label to $p$, else

- if only one neighbor has $\mathrm{V}=\{1\}$, assign its label to $p$, else

- If more than one of the neighbors have $V=\{1\}$, assign one of the labels to $p$ and make a note of the equivalences.

After completing the scan, the equivalent label pairs are sorted into equivalence classes and a unique label is assigned to each class. As a final step, a second scan is made through the image, during which each label is replaced by the label assigned to its equivalence classes. For display, the labels can be of different colors. 


\subsubsection{Moore's Neighbor Tracing:}

In this algorithm, it takes a pattern group of white pixels on a background of black pixels. After locating a white pixel from the bottom leftmost set of pixels we take it as start pixel. Then from that pixel we extracted the contour by going around the pattern in a clockwise direction. By this, system traces all the group of pixels. The main idea is - every time it hits a black pixel it backtrack and go back to the last white pixel we were standing on. The algorithm terminates when one pixel is visited for the second time.

Start

- $\quad$ Set $\mathbf{S}$ to be empty.

- From bottom to top and left to right scan the cells of $\mathbf{F}$ until a white pixel, $\mathbf{s}$, of $\mathbf{R}$ is found.

- Insert $\mathbf{s}^{\prime}$ in $\mathbf{S}$.

- Set the current boundary point $\mathbf{p}$ to $\mathbf{s}^{\prime}\left(\mathbf{p}=\mathbf{s}^{\prime}\right)$

- Backtrack to the pixel from which s' was entered.

- Set $\mathbf{v}$ to be the next clockwise pixel in $\mathbf{N}(\mathbf{p})$.

- While v not equal to s' do

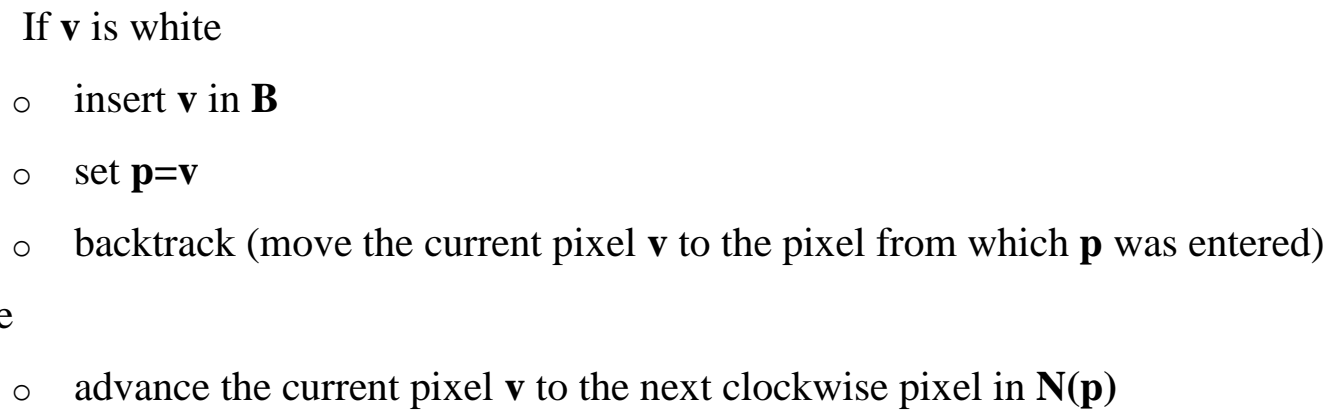

end While

End 


\subsection{D Visualization Techniques}

\subsubsection{Ray Casting Technique}

Among a several number of 3D Volume rendering techniques, Ray casting is one which allows the best uses of 3D data and does not include any geometric structure on it. Ray casting algorithms produce an image by casting a ray through the volume for each image pixel and integrating the color and opacity along the ray [31]. Ray casting is also referred as ray tracing in case of volume rendering as the volume rendering algorithm operates by tracing rays into the volume parallel to the viewing direction [29]. The term volume rendering is used to visualize 3D arrays of sampled data [29]. The elements of these arrays are each called voxels. This technique basically processes $2 \mathrm{D}$ prognosis of a colored semitransparent volume to produce sampled 3D images. In order to perform the operation of volume rendering, "Osirix" software[42] has been used as the software uses Ray Casting Technique.

The proposed volume rendering algorithm uses ray casting method which is based on Blinn/Kajiya [30, 34] model. It is assumed in this model that the volume is penetrated by a ray $\mathrm{R}$ and has a density $\mathrm{D}(\mathrm{x}, \mathrm{y}, \mathrm{z})$.

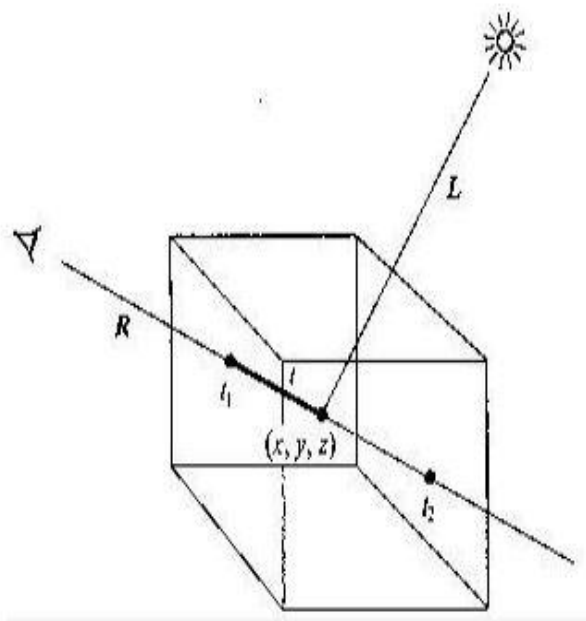

Fig. 2.5.1: Blinn/Kajiya model- A ray R cast into a scalar function of three spatial variables

An Illumination $I(x, y, z)$ is found at each point $(x, y, z)$ from the light sources along with the ray $\mathrm{R}$. The intersperse of the intensity rest upon this value, a reflection function $\mathrm{P}$ and density $\mathrm{D}(\mathrm{x}, \mathrm{y}, \mathrm{z})$. 
So, along the ray $\mathrm{R}$ the density function can be calculated as:

$$
D(x(t), y(t), z(t))=D(t)
$$

The illumination I can be parameterized from the source as:

$$
I(x(t), y(t), z(t))=I(t)
$$

And from a point $\mathrm{t}$ along the ray $\mathrm{R}$ the illumination intersperse is:

$$
I(t) D(t) \mathrm{P}(\cos \emptyset)
$$

Where $\mathbf{L}$ is the light vector from the point of interest and $\varnothing$ is the angle between $\boldsymbol{R}$ and $\boldsymbol{L}$. $\mathrm{I}(\mathrm{t})$ indicates how the light interspersed at point $(\mathrm{x}, \mathrm{y}, \mathrm{z})$ along the ray $\boldsymbol{R}$ to the eye.

The attenuation for the density function along a ray can be calculated as:

$$
\exp \left(-\tau \int_{t 1}^{t 2} D(s) d s\right)
$$

Where $\boldsymbol{\tau}$ is a constant for transforming density to attenuation.

The intensity created by the light arriving to the eye along the ray $\mathrm{R}$ is given by:

$$
B=\int_{t 1}^{t 2}\left(\exp \left(-\tau \int_{t 1}^{t 2} D(s) d s\right)\right)(I(t) D(t) P(\cos \emptyset)) d t
$$

\subsection{GPU Parallel Processing}

In order for the proposed approach to be carried out more efficiently, an improvement has been suggested in this segment of the chapter. The goal is to complete the desired task in minimum possible time with better output. As the title of this segment suggests, the technique to be used is GPU parallel processing.

The discovery and evolution of the programmable GPU has been taken place because of the rapidly growing need for real-time and high definition 3D graphics processing. It has evolved 
into multithreaded, parallel and multi-core chip system with exceptionally high computational capability. Hence came the idea to involve GPU parallel processing technique on our proposed method. To clarify the reason of the introduction of the aforementioned approach, the following table has been presented.

Table 1: Comparison of Computation Times

\begin{tabular}{|l|l|l|}
\cline { 2 - 3 } \multicolumn{1}{c|}{} & \multicolumn{2}{c|}{ Time (sec) } \\
\hline \multicolumn{1}{|c|}{ Proportion } & \multicolumn{1}{c|}{$\mathbf{1 6 0 x 1 2 8}$ pixels } & \multicolumn{1}{c|}{$\mathbf{2 1 0 x 1 8 2}$ pixels } \\
\hline 1 CPU thread & 184.091343 & 627.95773 \\
\hline 2 CPU threads & 196.874450 & 713.950154 \\
\hline $1 / 2$ CPU + 1/2 GPU & 98.867030 & 336.006175 \\
\hline $1 / 4$ CPU + 3/4 GPU & 49.657433 & 163.791901 \\
\hline $1 / 8$ CPU + 7/8 GPU & 39.236646 & 139.992048 \\
\hline GPU & 29.888206 & 111.724455 \\
\hline
\end{tabular}

All the experiments are carried out using the hardware specifications of GPU: GeForce 9500 GT, 1 MB DDR2, No of Processors = 4, No of core =32, RAM 1 GB, Frequency 1.35

GHz, DDR2 and CPU: Intel Core 2 Duo, 2.66 GHZ, No of cores available =2, No of thread=1, No of thread/core=1, Physical Memory =2 GB, DDR2 [36]

However, other than saving very significant amount of calculation time, parallel processing can help the research to achieve more accurate result in some of the steps compared to using the trivial single threaded operation on CPU. For example, on the step of noise reduction, use of GPU, the operation can be carried out faster and more efficiently.

The basic idea of GPU parallel processing is to divide the task (in terms of the code of the proposed programming language) into many sub-tasks. Then, it is important to assign blocks of memory on the GPU. The pipelining of the sub-tasks into those blocks of memory from the RAM is performed. The sub-tasks are carried out in the GPU simultaneously and upon completion of those sub-tasks, they are reconstructed and sent back to the RAM. It is important to undo the memory block allocation on GPU after the operation is completed. 
In order to the whole parallel processing technique to be applied, the research proposes the use of CUDA. CUDA ${ }^{\mathrm{TM}}$ was introduced by NVIDIA in November 2006. It is a general purpose parallel computing architecture. It contains new instruction set architecture and parallel programming model. 


\section{Chapter III}

\section{Proposed Method}

The proposed method is composed of four parts which are given below -

- Image Input

- Pre-Processing

- Processing

- Output

In the first stage, as input image, one Toshiba CTA image and two CTA images of artery of heart have been acquired. After acquiring the image, nearest neighbor interpolation method were performed for image scaling.

Then, moving on to the pre-processing stage where we used Gaussian Soothing for reducing color complexity. Later Luminosity method were for grayscaling where blue color was prioritized while converting the images. Finally Median Filtering has been used to reduce noises.

After this we proceed with the main processing part where the arteries were segmented by removing backgrounds from the images and determining pixel density in artery perimeters. Then the proposed algorithm determines the quantification of stenosis.

The output is divided into two part. The first part identifies the risk factor and the second part provides a 3D visualization of Coronary Arteries. 


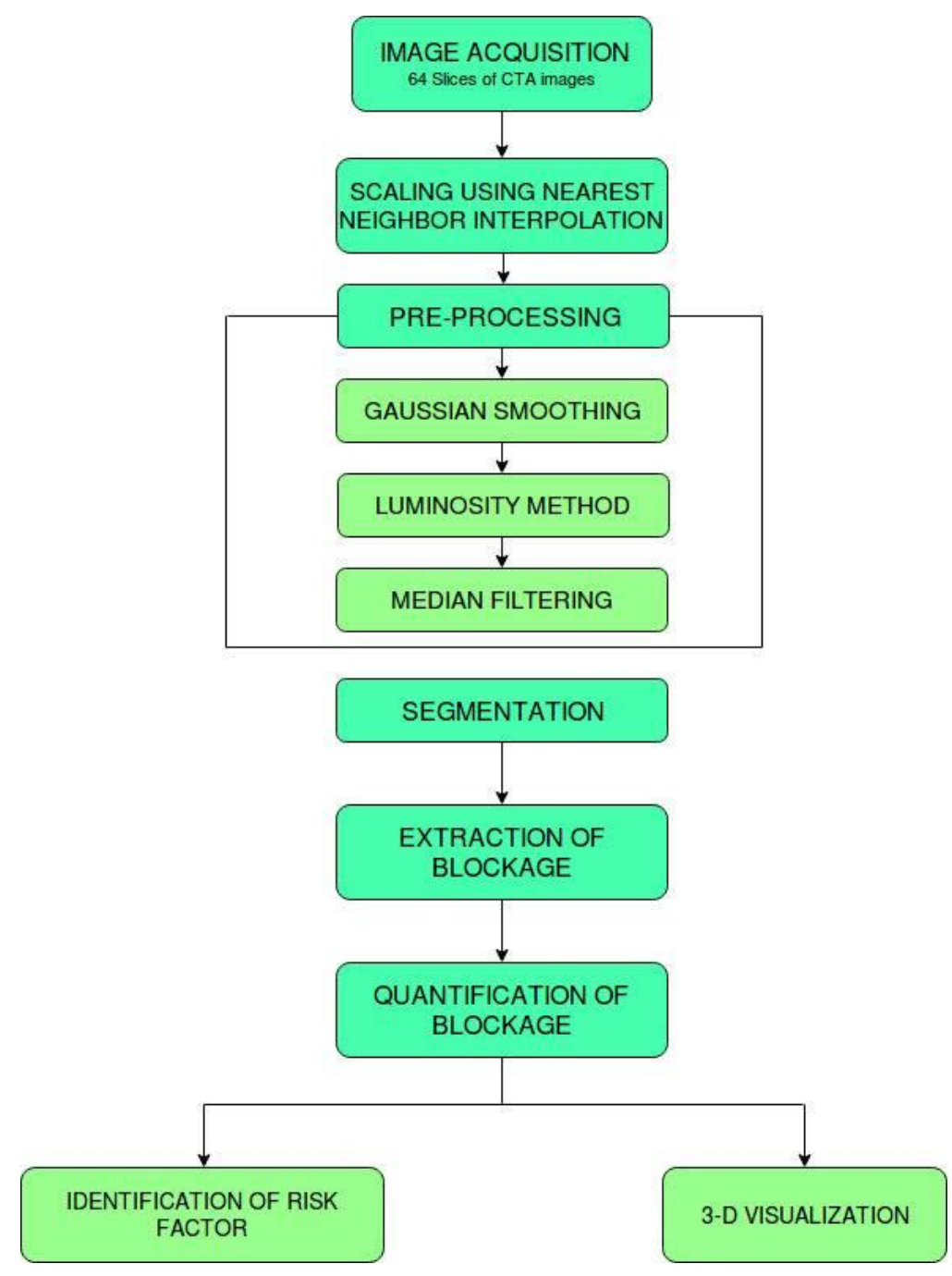

Fig. 3.1: Flowchart of the Proposed System.

\subsection{Input Image}

In order to apply the proposed algorithms and methods, two CTA images of 64 slices and one CTA image by Toshiba of artery of heart are used. The viewing angle of figure 3.1.1.a is $\mathrm{LAO} / \mathrm{RAO}=107, \mathrm{CRAN} / \mathrm{CAUD}=32$. The viewing angle of figure 3.1.1.b is $\mathrm{LAO} / \mathrm{RAO}=51$, $\mathrm{CRAN} / \mathrm{CAUD}=72$. 


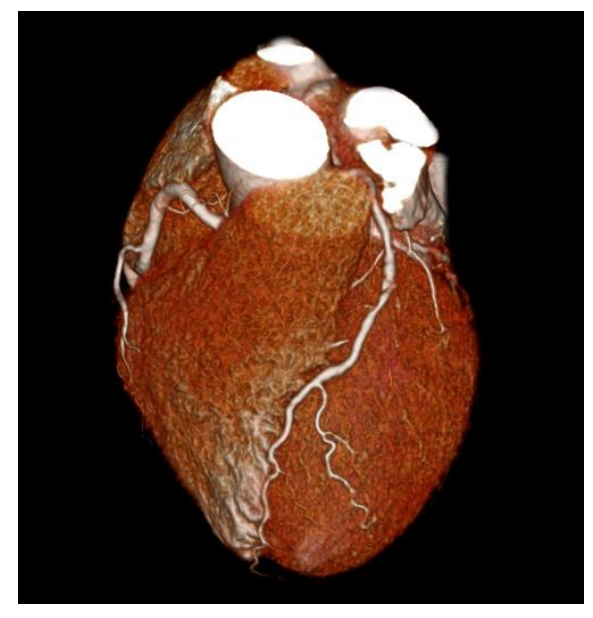

(a)

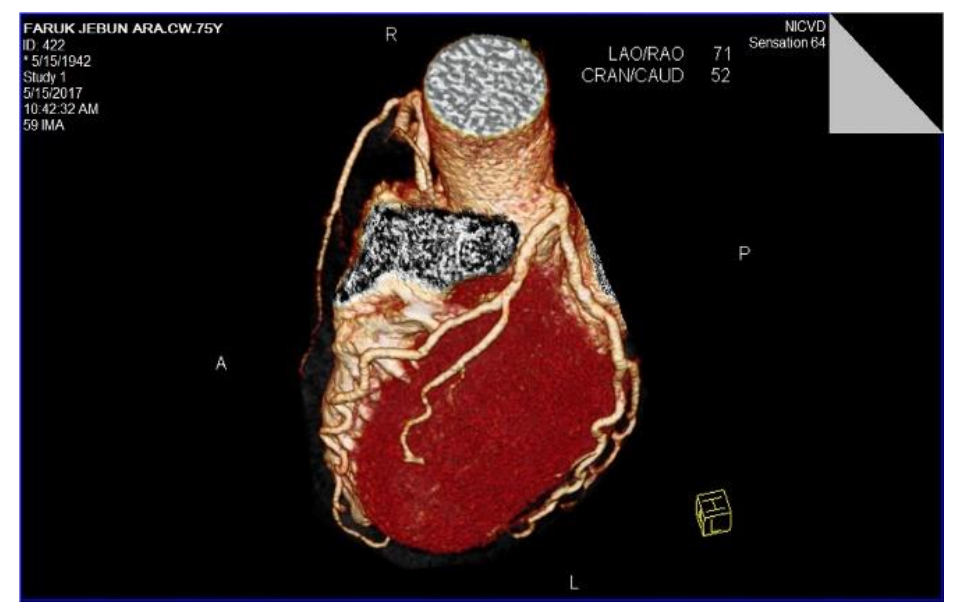

(b)

Fig. 3.1.1: (a,b) Two CTA image of 128 slices

\subsection{Image Scaling Using Nearest Neighbor Interpolation}

In future procedure, every single pixel will be counted for vast calculation. As the gained image's resolution, it will create problem in smooth calculation. So, nearest neighbor interpolation theory $[7,8]$ has been applied to enlarge the resolution. Rather than calculate an average value by some weighting criteria or generate an intermediate value based on complicated rules, this method simply determines the "nearest" neighboring pixel, and assumes the intensity value of it. The system is mainly applied based on the ratio of previous and past width and height, multiplied with the previous resolution. The resolution of figure 1.a and 1.b has been converted into $3000 \times 1800$ respectively, and figure 1.c in $2100 \times 2100$.

$$
\left.\begin{array}{l}
x \_ \text {ratio }=\frac{w_{1}}{w_{2}} \\
y_{-} \text {ratio }=\frac{h_{1}}{h_{2}}
\end{array}\right\} w_{2}, h_{2} \neq 0
$$

\subsection{Pre-processing}

The CTA images are needed to be pre-processed to reduce complexities in further process. First 


$$
G(x, y)=\frac{1}{2 \pi \sigma^{2}} e^{-\frac{x^{2}+y^{2}}{2 \sigma^{2}}}
$$

of Gaussian smoothing with 9x9 kernel and sigma $=4$ is applied .The Gaussian outputs a 'Weighted Average' of each pixel's neighborhood $[9,10]$, with the average weighted more towards the value of the central pixels. It will make smoother edge by reducing color contrast, details and noise.
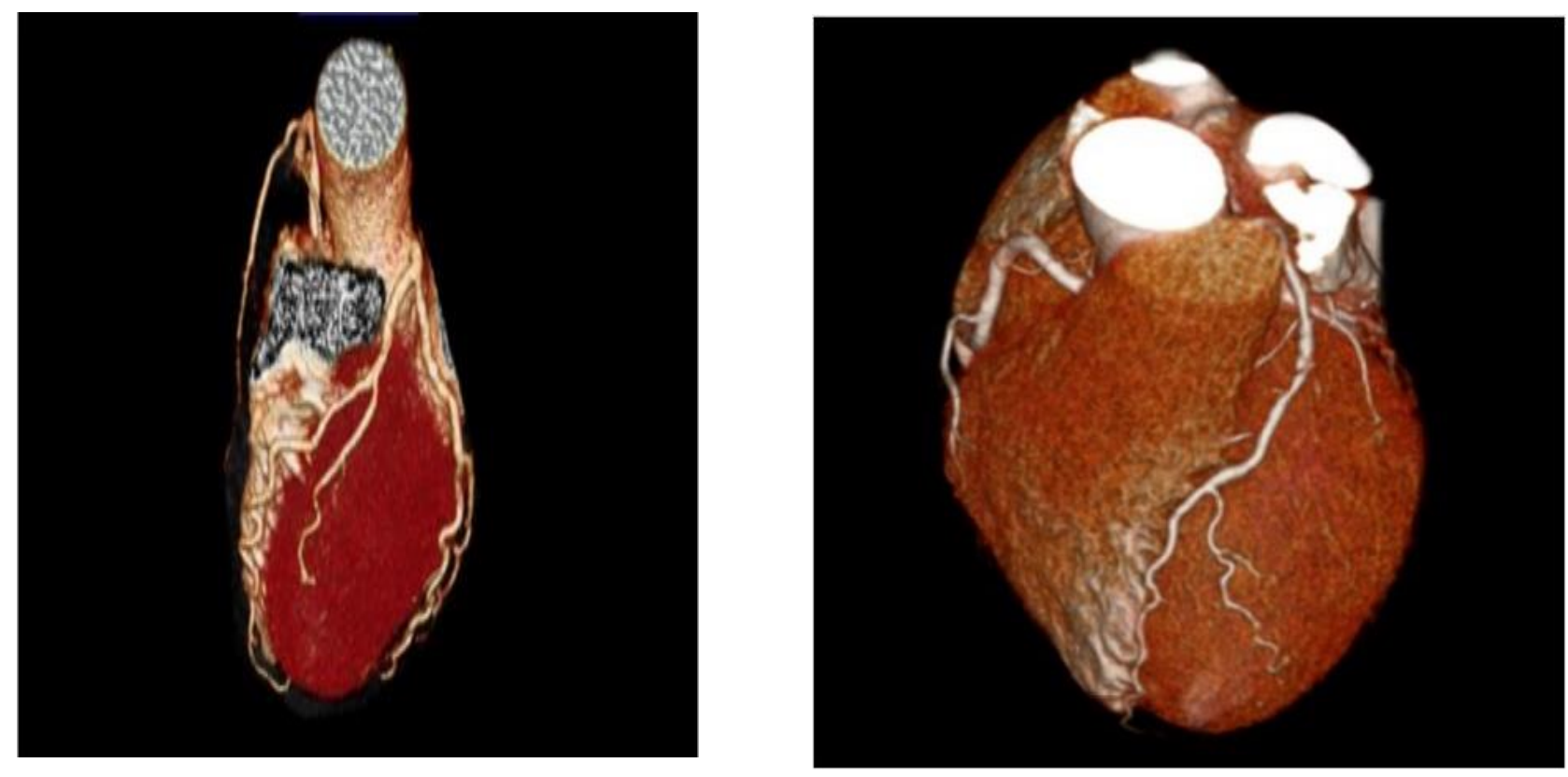

Fig. 3.3.1: Gaussian smoothen image where sigma $=4$

Furthermore, the images then converted into grayscale using luminosity method [11]. It averages the values, but it forms a weighted average to account for human perception. The images are more sensitive to red and blue than other colors, so red and blue are weighted most heavily. The formula for luminosity is:

$$
0.54 * R+0.39 * G+0.07 * B
$$



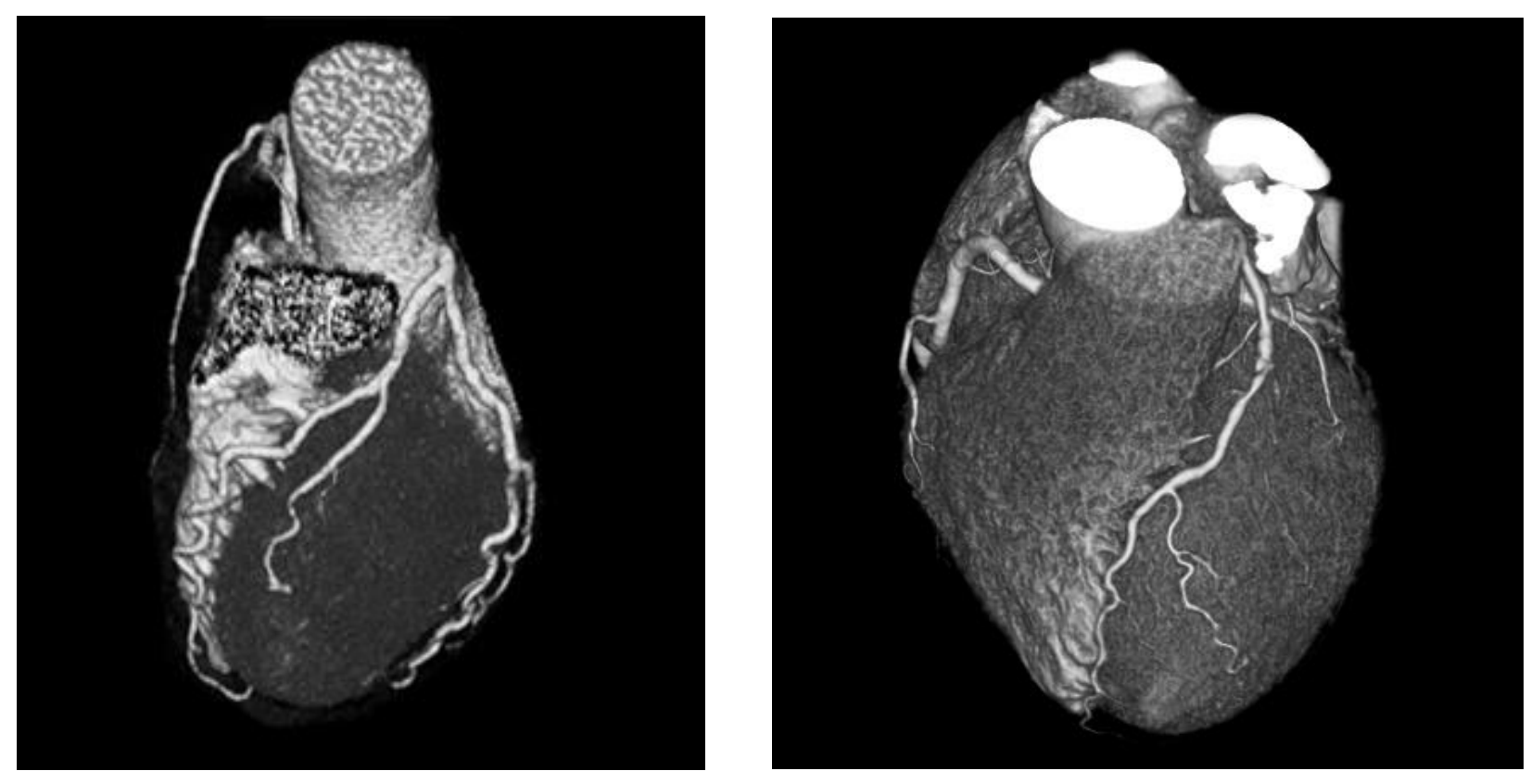

Fig. 3.3.2: Grayscale conversion using luminosity method.

Furthermore, to reduce noise median filtering has been used [12] gives vigorous average of the pixels. It is performed by the neighboring pixels that are sorted out and then the pixels are replaced by the median value of all the sorted pixels and if the neighboring pixels are even in number, then the average value of the middle two pixel value is used for the replacement.

\subsection{Segmentation of Coronary Artery}

In the coronary artery detection part, the system aims to detect the major parts or artery as block in the minor part doesn't fact a lot .Otsu Thresholding has been applied for thresholding. This algorithm assumes that an image has two types of pixels (foreground pixels and background pixels), it then calculates the optimum threshold separating the two classes so that their combined spread is minimal, or equivalent, so that their inter-class variance is maximal [13-15]. In this method, a threshold value is searched that minimizes intra-class variance, defined as a weighted sum of variances of the two classes:

$$
\sigma_{\omega}^{2}(t)=\omega_{0}(t) \sigma_{0}^{2}(t)+\omega 1(t) \omega_{1}^{2}(t)
$$


Weights $\omega_{0}$ and $\omega_{1}$ are the probabilities of the two classes separated by a threshold $t$ and $\boldsymbol{\sigma}_{0}^{2}$ and $\boldsymbol{\sigma}_{1}^{2}$ are variances of these two classes. The class probability $\omega_{0,1}(t)$ is computed from the $\boldsymbol{L}$ bins of the histogram:

$$
\begin{aligned}
& \omega_{0}(t)=\sum_{i=0}^{t-1} p(i) \\
& \omega_{1}(t)=\sum_{i=t}^{L-1} p(i)
\end{aligned}
$$

Otsu shows minimizing the intra-class variance and maximizing inter-class variance is equivalent.

$$
\begin{gathered}
\sigma_{b}{ }^{2}(t)=\sigma^{2}-\sigma_{\omega}{ }^{2}(t) \\
=\omega_{0}\left(\mu_{0}-\mu_{T}\right)^{2}+\omega_{1}\left(\mu_{1}-\mu_{T}\right)^{2} \\
=\omega_{0}(t) \omega_{1}(t)\left[\mu_{0}(t)-\mu_{1}(t)\right]^{2}
\end{gathered}
$$

This is expressed in terms of class probabilities $\boldsymbol{w}$ and class means $\boldsymbol{\mu}$, while the class mean $\boldsymbol{\mu}_{\mathbf{1 0}, \mathbf{1}, \boldsymbol{T}}$ $(\boldsymbol{t})$ is:

$$
\begin{aligned}
& \mu_{0}(t)=\sum_{i=0}^{t-1} i \frac{p(i)}{\omega_{0}} \\
& \mu_{1}(t)=\sum_{i=t}^{L-1} i \frac{p(i)}{\omega_{1}}
\end{aligned}
$$

Now based on these, thresholding will be applied with the high band pass $=141$ and low band pass $=255$. It deducted the unnecessary background and arteries then become able to visualize (figure 4). Furthermore, it will create difference between connected and not connected region which is needed to segment the artery from heart. 


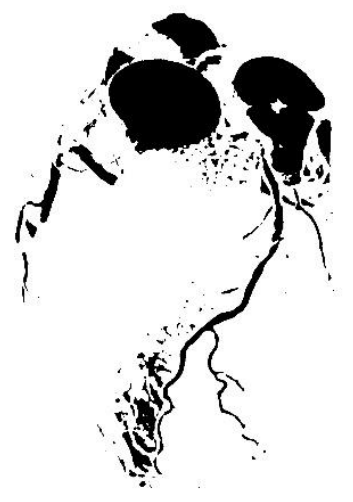

(a)

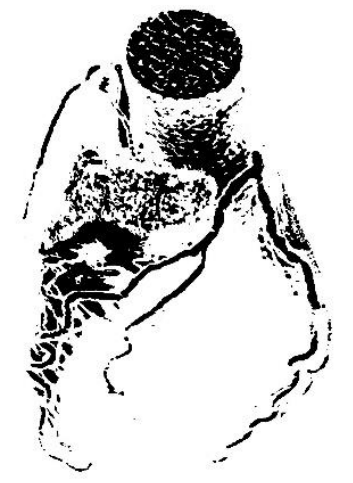

(b)

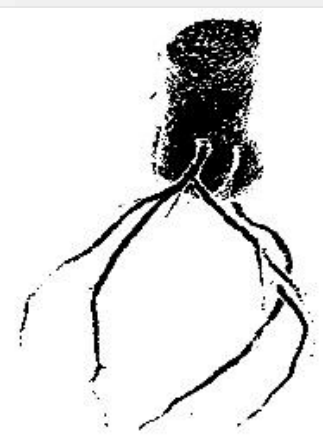

(c)

Fig 3.4.1: (a) Rejecting background from Toshiba CTA, (b, c) Rejecting background from two 128 Slice CTA

If the larger connected (area) pixels and every lower connected pixels aka noise can be removed, the only vessel will be left. Now, the objects in the binary image of vessels needs to be a solid otherwise multiple cells will be counted instead of one. These can be done by filling the background regions using morphological reconstruction which recovers

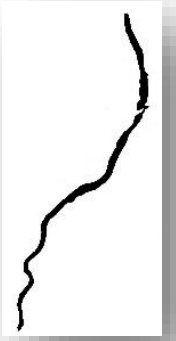

(a)

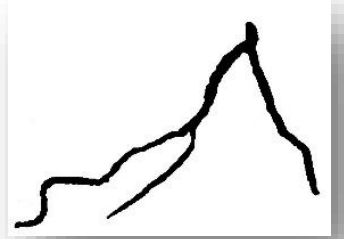

(b)

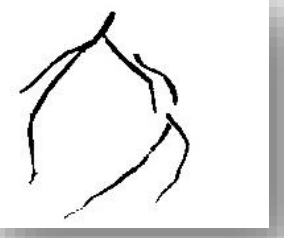

(c)

Fig. 3.4.2: (a) Segmented arteries from Toshiba CTA, (b, c) Segmented Artery from two 128 slices of CTA.

the minima that are not connected with in an object boundary. This flood-fill operation [16] area applied the binary image where it changes the connected background pixels to foreground. Mainly this operation will be occurred till it reaches the boundaries. In a connected bounded region, if 
there are pixels with non-zero pixel value, then it will reconstruct it and make background pixels to foreground. Mainly this operation will be occurred till it reaches the boundaries.

8-connected components analysis method has been applied to count total connected components [17-20]. It starts scanning from a point and runs till reaching to the starting point based on checking connected neighbor. After locating a white pixel from the bottom leftmost set of pixels it takes the position as start pixel. Then from that pixel it extracted the contour by going around the pattern in a clockwise direction. Following this it traces all the group of pixels and sparely trace region. This tracing is performed by using Moore's Neighbor Tracing algorithm [21-24] Total numbers of white pixels are counted as the area of the certain bounded part. Moreover, as the artery has become one connected region, there will be some other parts with heart's artery. As they are larger in size than the artery's area delete them after with a condition if the system measure the area or total connected components in vessel region, than area greater than this, will not accepted. Similarly, after deducting the larger upper heart part, the system needs to remove noises as well as unwanted components created for rest of heart's organ or minor artery or foreground side color. By trial and error method, its gained that first heart's major artery area is 18,500 pixel, second heart's major artery area is 43,865 pixel and third ones area is 41,000 pixel. If areas correspondingly less or greater than this is deducted, than only artery of heart will be segmented (figure 5).

Then, binary image is inverted by reversing binary value of the image. To detect the perimeter or pixel location of boundary, First of all, boundaries of each cells are traced based on the connectivity of white pixels from black pixels backgrounds canning from left bottom left corner to each rows going upwards and again starting from leftmost column to right until stop from where it started if it can complete a loop, then it'll be traced as boundary. All the pixels locations are stored in a dataset.

The pixels intensity of each perimeter are replaced with color (green) with thickness 1.5. Finally the processed images are plotted merging with main images by adding logic (figure 6). 


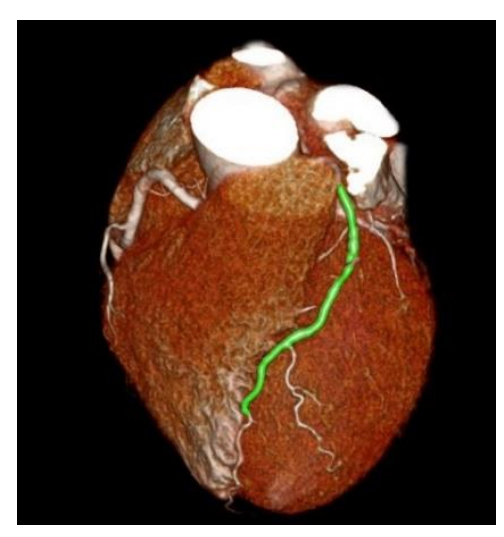

(a)

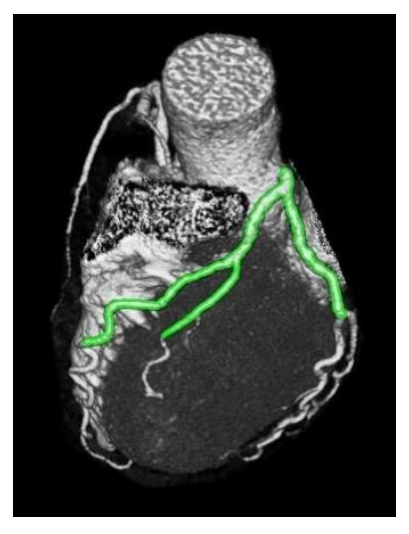

(b)

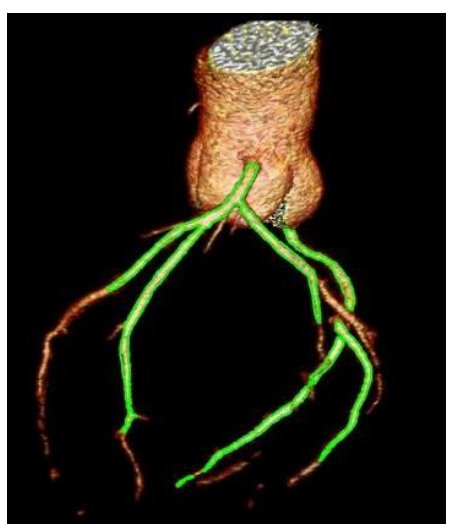

(c)

Fig. 3.4.3: Pixels Intensity of perimeters in green, (a) Toshiba CTA (b,c) two 128 slices CTA

\subsection{Quantification of Blockage}

By using the proposed algorithm, blockage of artery is measured in percentage. The perimeter pixels locations are stored in datasets. Using the dataset's row and column value first of all get the minimum and maximum value and only make range till its midpoint as in average case blockage in minor artery doesn't affect either its huge or not. But as little blockage in major artery effects a lot, so only this part is counted. Now to program will start scanning from a starting point and will end after returning to the starting point. This make two edges based on same column with different row location. Normally, going top to bottom artery get narrower with a fix ratio. The program connects line to check corresponding same column and different row position. If It after sudden point distance become lower continuously and then began to increase in size, and return to normal ratio, then an area starting from the decreasing to increasing part is captured that can be said the region of interest. By connecting column value of decreased and increased beginning points, color lines can be drawn from connection lines pixels to ROI's contours pixel position .As a result blockage has been colored with color. Further, finding the closest point of these two contours, need to measure distance from connecting lines closest pixel to artery's second edge part where value of column both are same. And again measure distance to that point of connection line to artery' first edge part where conditions are same and divide them. Finally the percentage of the artery block will be measured. 
Insert dataset;

$[\mathrm{x}, \mathrm{y}]=[$ row, column $]$;

find Ymax, Ymin;

$\%$ taking the major artery part

Range $=(\mathrm{Ymax}+\mathrm{Ymin}) / 2 ;$

for $\mathrm{I}=$ ystart $:$ range

process (xstart ,ystart ,xend,yend ) :

if $($ ystart $==$ yend $)$

if (hasVisited==flase)

if ( edgeA: $\mathrm{y}==$ edgeB:y)

$\%$ to overcome $\theta$ (theta)

for $\mathrm{j}=($ edgeB-50) $:($ edgeB +50$)$

$\operatorname{dis}=\sqrt{(e d g e A: x-e d g e B: x)^{2}+(e d g e A: y-e d g e B: y)^{2}} ;$

store the values in Array1[ ];

hasVisited = true;

end

end

end

if ( dis < dis.previous)

check if (dis is continuously decreasing )

comment $=$ narrower minor artery part;

end

else if (dis is continuously decreasing \&

after sudden time start increasing )

ROI(Y decrease to Y increase ) ;

connect $=\sqrt{\left(X_{\text {decrease }}-X_{\text {increase }}\right)^{2}+\left(Y_{\text {decrease }}-Y_{\text {increase }}\right)^{2}}$

drawRedLine :

connect $(\mathrm{x}, \mathrm{y})$ to $\mathrm{ROI}(\mathrm{x}, \mathrm{y})$;

blockSize :

where drawLine $=$ lowest :

$\mathrm{p} 1=(\mathrm{x} 0, \mathrm{y} 0)=\mathrm{ROI}(\mathrm{xend}, \mathrm{yend}) . \mathrm{CPoint}$;

$\mathrm{p} 2=(\mathrm{x} 1, \mathrm{y} 1)=\operatorname{connect}(\mathrm{x}, \mathrm{y}) \cdot$ CPoint; 


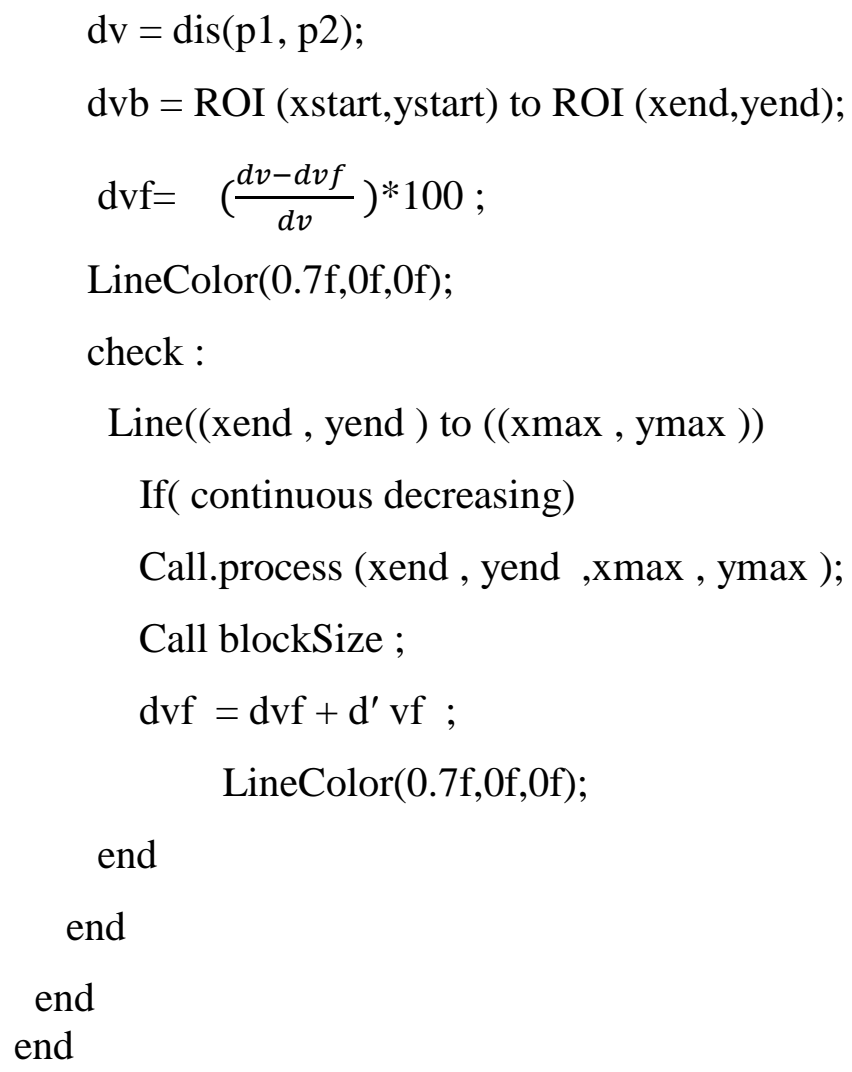

\subsection{D Visualization}

After getting the Region of Interest (ROI) from the segmentation part, the 2D DICOM images are being extracted to be used for 3D Volume Rendering.

According to Levoy [33], Ray casting technique involves an algorithm which simplify the integration of the intensity of the light towards the eye. This is done by a method called "additive reprojection". In this method, the projection of a voxel is done in a particular viewing direction which provides an intensity towards the viewing plane. The voxels are assigned to a maximum opacity in order to control the visualization of the volume. The lighting model combines the reflection and transmission light from each voxel.

This approach can be modeled in the figure below: 


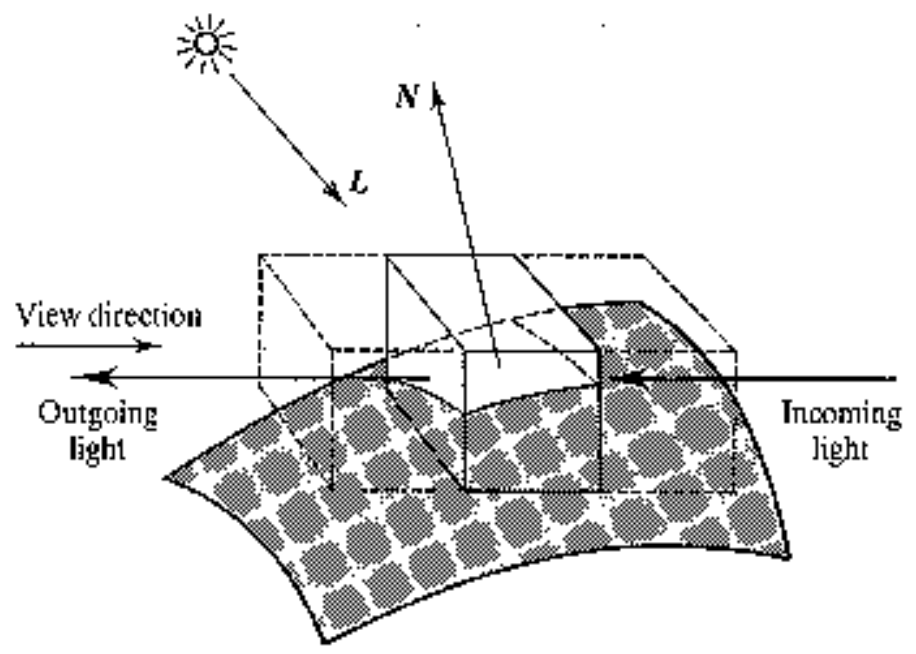

Fig. 3.6.1: Illustration of the "Additive Reprojection" method

The interpolation produces the opacity and the color along the ray and they are merged with each other and combining with the background by compositing in front-to-back. The technique consists of two pipelines - a visualization and a classification pipeline. Using the column metric composition, the output of the two pipelines then combined to generate the final image. The visualization pipeline involves shading each voxel in the volume data by calculating a local gradient and thus the voxel normal is produced to use it as an input of standard Phong shading model to generate an intensity. At last, for every voxel in the volume data set, a three color component intensity is produced as the output of this pipeline.

This method involves basing the opacity of each voxel on the gradient and the gradient is then multiplied by the opacity. In the classification pipeline each voxel is associated with an opacity and the color parameters from the shading model are used. In this pipeline, each voxel stands for an X-ray absorption coefficient which can be calculated as shown below:

$$
\alpha(X)=\left\{\begin{array}{c}
\alpha_{V_{n}+1}\left\{\frac{V(X)-f_{V_{n}}}{f_{V_{n}+1}-f_{V_{n}}}\right\} \\
+\alpha_{V_{n}}\left\{\frac{f_{V_{n}+1}-V(X)}{f_{V_{n}+1}-f_{V_{n}}}\right\} \\
\text { if } f_{V_{n}} \leq V(X) \leq f_{V_{n}+1} \\
0 \text { otherwise }
\end{array}\right.
$$

This gives two values for each voxel:

1. $\mathbf{C}(\mathbf{X})$ - The shade generated by the local gradient

2. $\alpha(\mathbf{X})$ - The opacity calculated from the color parameters 
These two values are then combined to produce the final pixel intensity. The formula of the standard transparency for each voxel along the ray $\mathrm{R}$ is:

$$
C_{\text {out }}=C_{\text {in }}(1-(x))+c\left(x_{i}\right) \alpha\left(x_{i}\right)
$$

For each voxel along the ray the,

$C_{\text {out }}$ Represents the outgoing intensity.

$C_{\text {in }}$ Represents the incoming intensity.

The trilinear interpolation of each voxel considers neighboring voxels which yields values lying along the ray $\mathrm{R}$. The pseudo code of the procedure is given below:

\section{Procedure TraceRay, (u) begin}

$$
\begin{aligned}
& \mathrm{C}(\mathrm{u})=0 ; \\
& (\mathrm{u})=0 ; \\
& \mathrm{x}_{1}=\operatorname{First}(\mathrm{u}) ; \\
& \mathrm{x}_{2}=\operatorname{Last}(\mathrm{u}) ; \\
& \mathrm{U}_{1}=\left[\operatorname{Image}\left(\mathrm{x}_{1}\right)\right] ; \\
& \mathrm{U}_{2}=\left[\operatorname{Image}\left(\mathrm{x}_{2}\right)\right] ;
\end{aligned}
$$

|Loop through all samples falling within data|

\section{For $\mathbf{U}=\mathbf{U}_{1}$ to $\mathrm{U}_{2}$ do begin}

$\mathrm{x}=\operatorname{Object}(\mathrm{U})$;

$\mid$ If sample opacity $>0 \mid$

|then resample color and composite into ray|

$$
\text { (U) = Sample }(, \mathrm{x}) \text {; }
$$

\section{If $(\mathrm{U})>0$ then begin}

$$
\begin{aligned}
& \mathrm{C}(\mathrm{U})=\text { Sample }(\mathrm{C}, \mathrm{x}) ; \\
& \mathrm{C}(\mathrm{u})=\mathrm{C}(\mathrm{u})+\mathrm{C}(\mathrm{U})(1-(\mathrm{u})) \\
& (\mathrm{u})=(\mathrm{u})+(\mathrm{U})(1-(\mathrm{u})) ; \\
& \text { end }
\end{aligned}
$$

end

end TraceRay; 
This uses a full 26 voxel neighborhood and thus produces a smoothly shaded output image.

\subsection{GPU Parallel Processing}

This architecture can be used on various steps of the proposed methodology. In CUDA, it is assumed that both host and device maintain their own DRAM. Host memory is allocated using malloc and device memory is allocated using cudaMalloc. CUDA threads are assigned a unique thread ID that identifies its location within the thread, block and grid. In the preprocessing stage, the RGB to Grayscale conversion can be done by using "rgbaToGreyscaleCudaKernel()" method on CUDA[37]. The luminosity method that has been suggested in the earlier single threaded technique for color conversion can also be used here on CUDA by doing slight modification inside the method.

Again, the Otsu's thresholding method proposed after the color conversion step in the single threaded approach can be carried out on CUDA using the following method (the pseudocode has also been provided) [38]:

Main()

\{

Define block and grid

Kernal_Histogram(numOfPixels, image, histogram)

Calculate threshold from histogram

Kernal_Threshold(numOfPixels, image, threshold)

\}

Kernal_Histogram (numOfPixels, image, histogram)

\{

Declare shared memory subHist [numOfThreads] [256];

for each data pixels in window

$$
\text { subHist [threadId] [currentPixelValue]++; }
$$

end for

Apply scan to merge subHist into histogram

\} 
Kernal_Threshold (numOfPixels, image, threshold)

\{

for each data pixels in window

if (

currentPixelValue $<$ threshold)

currentPixelValue = BLACK;

else

currentPixelValue = WHITE;

end for

\} 


\section{Chapter IV}

\section{Results}

\subsection{Simulation Methodologies}

Using the proposed method, three samples of coronary artery images from different patients with different heart conditions have been analyzed and compared to determine the accuracy and efficiency of the Algorithm.

(1) First of all, manual opinion of certified cardiologists have been taken into consideration.

(2) Secondly, a manual method which compares the ratio of diameters between healthy portion of coronary artery and a portion with some amount of blockage. While using the manual method, the following expression have been used to calculate the percentage of artery blockage.

$$
\text { Percentage of blockage }=\left(1-\left(\frac{d_{v_{b}}}{d_{v}}\right)\right) \times 100 \%
$$

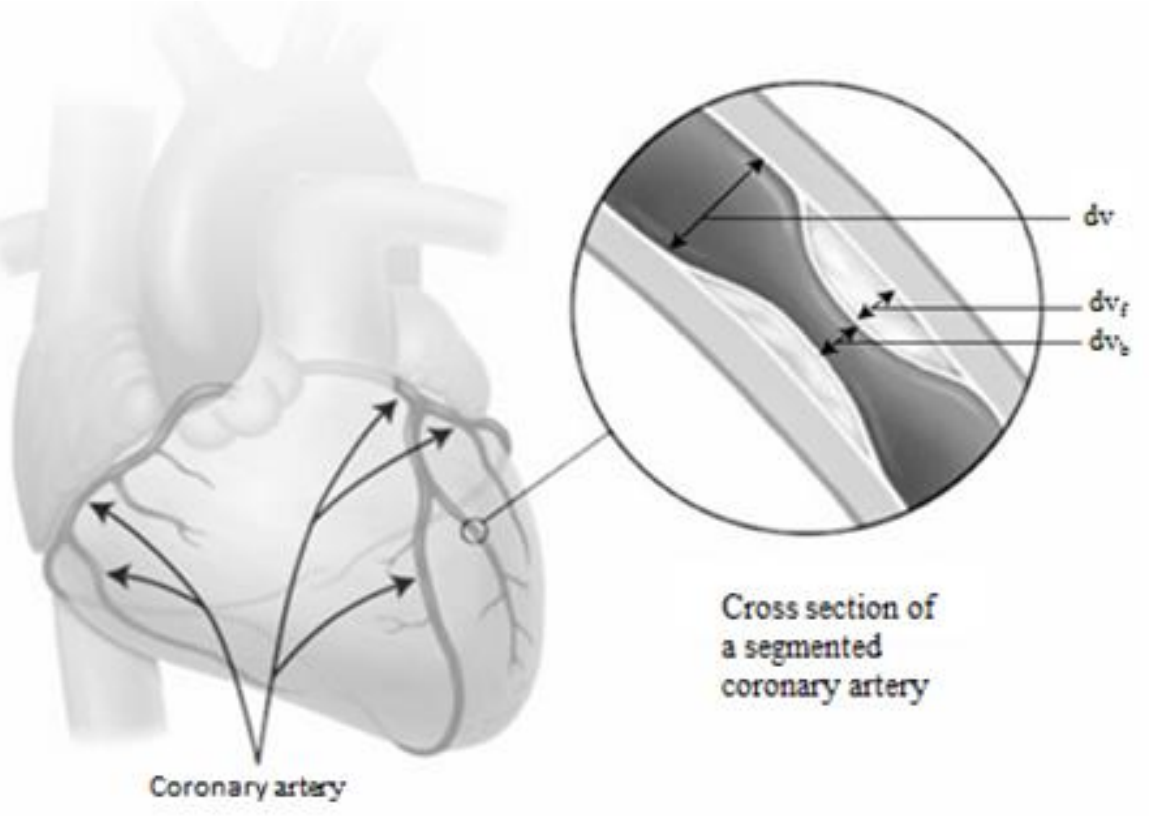

Fig. 4.1.1: Illustration of the degree of Artery blockage

(3) Finally, the proposed method have been used to determine the percentage of blockage. 


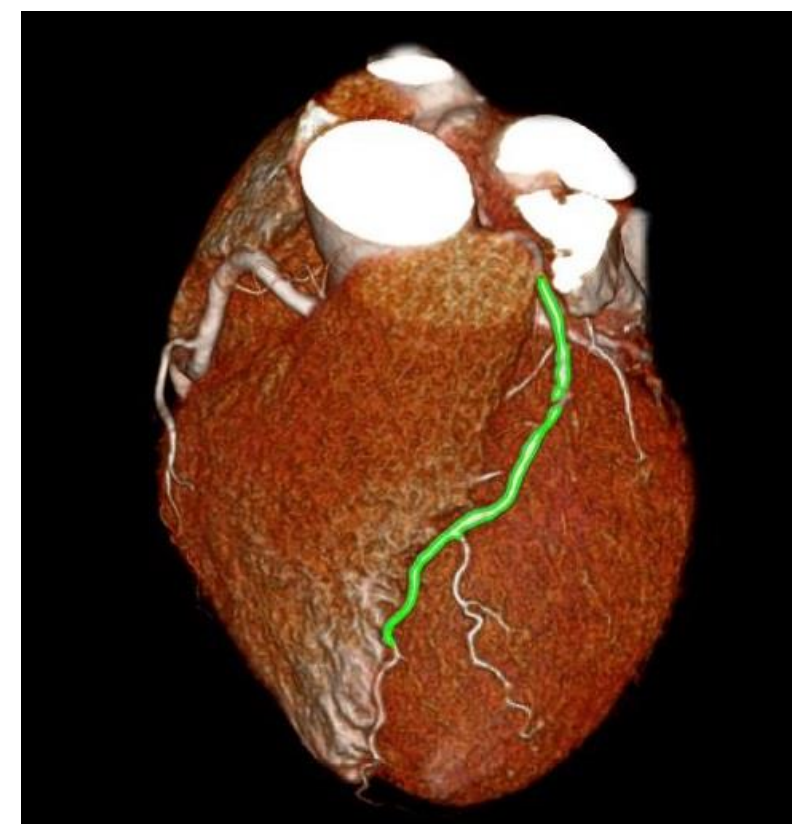

(a)

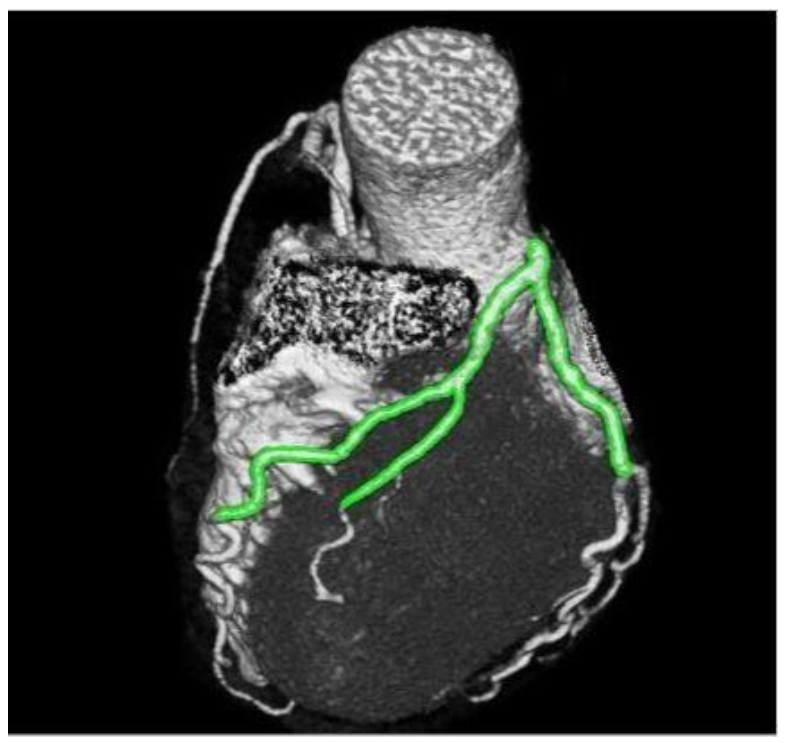

(b)

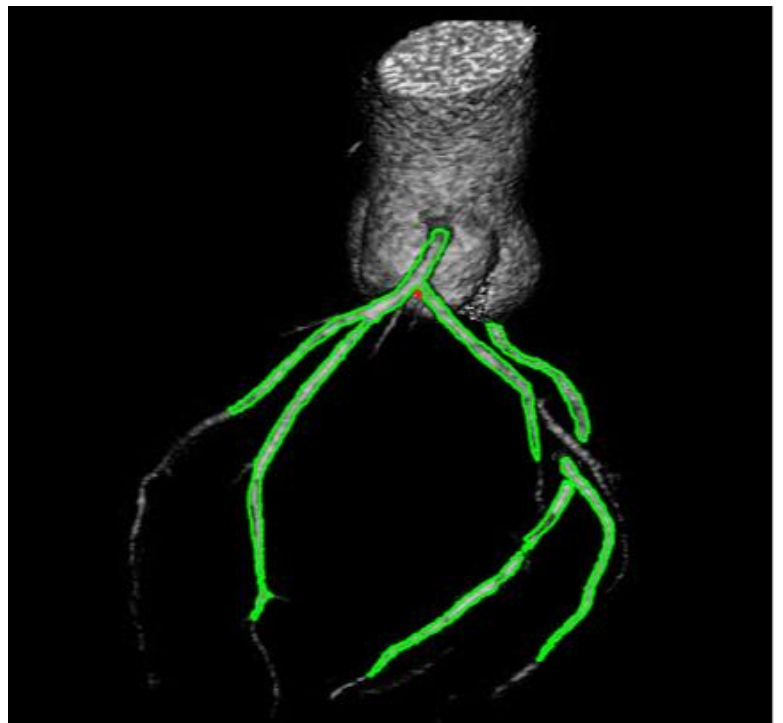

(c)

Fig. 4.1.2 Coronary Arteries (a) sample 1 (b) sample 2 (c) sample 3 
In the above samples of coronary arteries, moderate degree of blockage have been found in sample 3. The portion with blockage is shown in below figure:

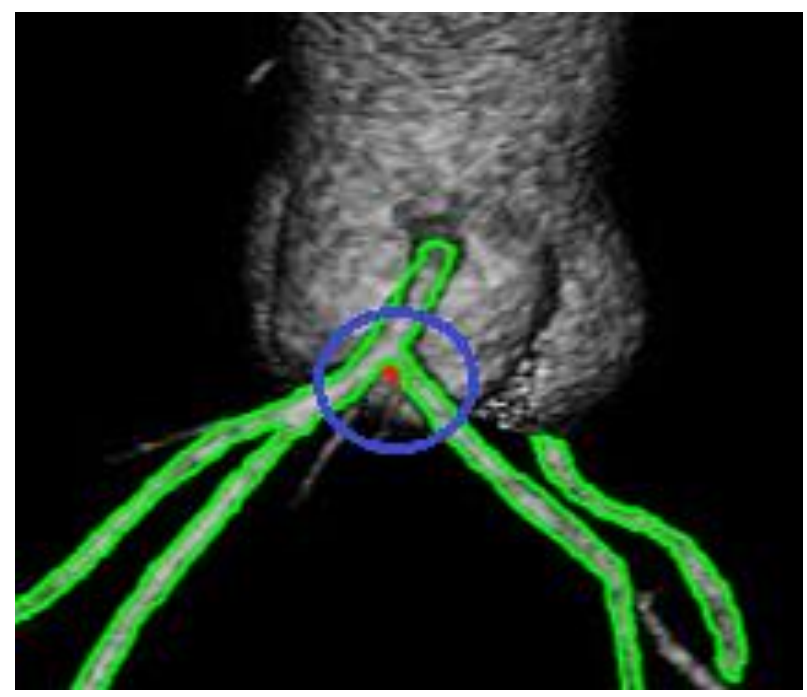

Fig. 4.1.3: Detected Blockage in Sample 3.

\subsection{Identification of Degree of Stenosis}

After acquiring the percentage of blockage using above mentioned methods, the degree of stenosis have been determined using the following table:

Table 2: Identification of Degree of Stenosis

\begin{tabular}{|c|c|c|}
\hline Degree of Stenosis & Percentage of Blockage & Evaluation \\
\hline Mild Coronary Stenosis & $(<50 \%)$ & $\begin{array}{c}\text { Drug Treatment will be } \\
\text { Appropriate }\end{array}$ \\
\hline Moderate Coronary Stenosis & $(50 \%-70 \%)$ & $\begin{array}{c}\text { Drug Treatment and / or Stent } \\
\text { Placement }\end{array}$ \\
\hline High Coronary Stenosis & $(>70 \%)$ & Stent Placement / Bypass \\
& & surgery \\
\hline
\end{tabular}


Now the table given below compares the differences among various approaches of quantifying the coronary artery blockage -

Table 3: Comparing the Percentages of Heart Blockage Using Specified Methods

\begin{tabular}{|c|c|c|c|c|c|c|c|c|}
\hline $\begin{array}{c}\text { Sample } \\
\text { No. }\end{array}$ & $\begin{array}{c}\text { Block \% } \\
\text { According } \\
\text { to Doctor's } \\
\text { Opinion }\end{array}$ & $\begin{array}{c}\text { Degree } \\
\text { of } \\
\text { Stenosis }\end{array}$ & $\begin{array}{c}\text { Block \% } \\
\text { According } \\
\text { to Manual } \\
\text { Method }\end{array}$ & $\begin{array}{c}\text { Degree } \\
\text { of } \\
\text { Stenosis }\end{array}$ & $\begin{array}{c}\text { Block \% } \\
\text { According } \\
\text { to } \\
\text { Proposed } \\
\text { Algorithm }\end{array}$ & $\begin{array}{c}\text { Degree } \\
\text { of } \\
\text { Stenosis }\end{array}$ & $\begin{array}{c}\text { Error \% } \\
\text { with } \\
\text { Doctor's } \\
\text { Opinion }\end{array}$ & $\begin{array}{c}\text { Error \% } \\
\text { with } \\
\text { Manual } \\
\text { Method }\end{array}$ \\
\hline $\begin{array}{c}\text { Sample } \\
1\end{array}$ & 10 & Mild & 10 & Mild & 12 & Mild & 20 & 20 \\
\hline $\begin{array}{c}\text { Sample } \\
2\end{array}$ & 20 & Mild & 25 & Mild & 27 & Mild & 35 & 8 \\
\hline $\begin{array}{c}\text { Sample } \\
3\end{array}$ & 55 & Moderate & 60 & Moderate & 62 & Moderate & 12.72 & 3.33 \\
\hline
\end{tabular}

A comparison of results from the three approaches to block detection is visualized in the bar charts below.

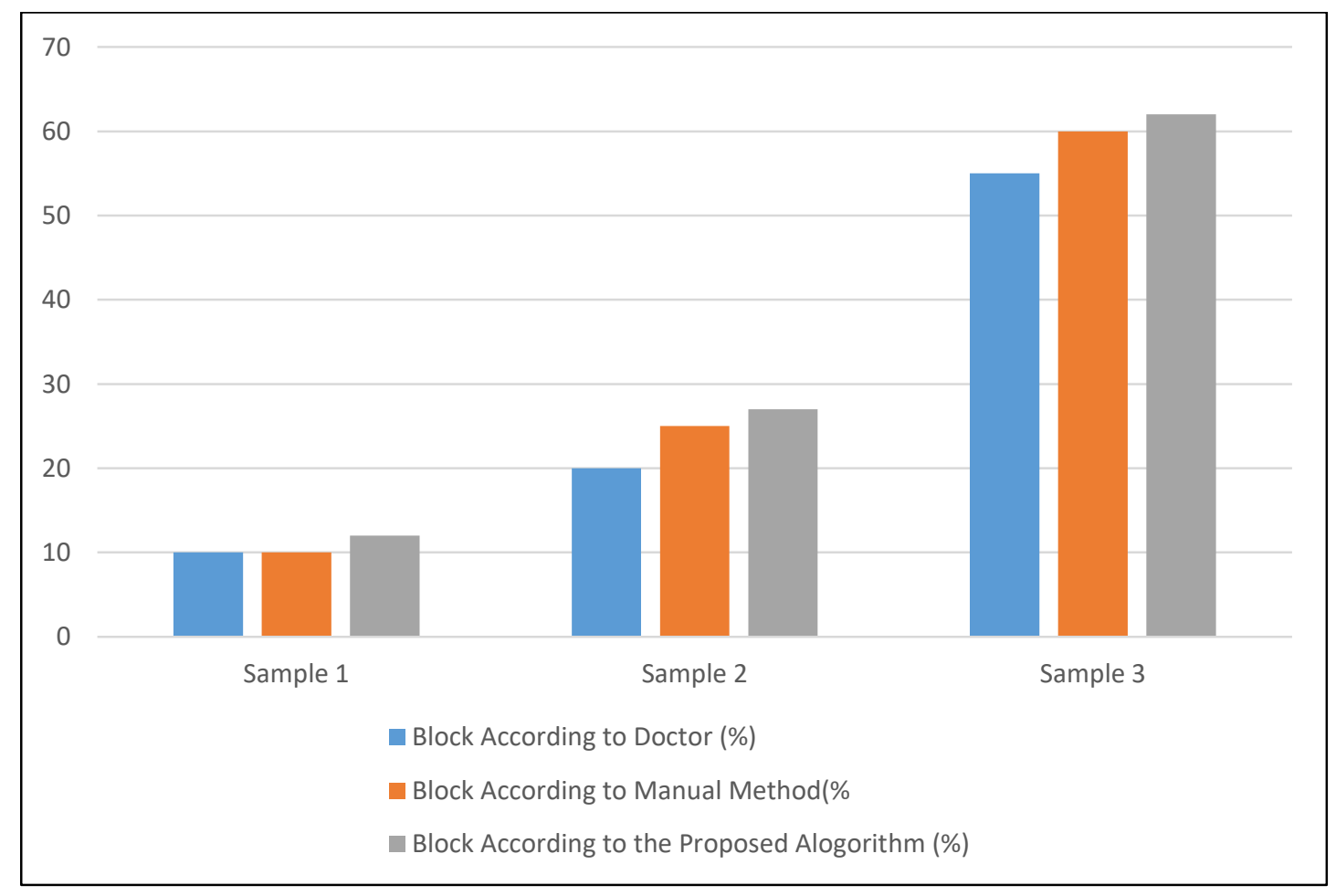

Fig. 4.2.1: Comparing the Percentages of Heart Blockage Using Specified Methods 
A comparison of error percentages among the proposed method and existing methods is visualized in the bar charts below.

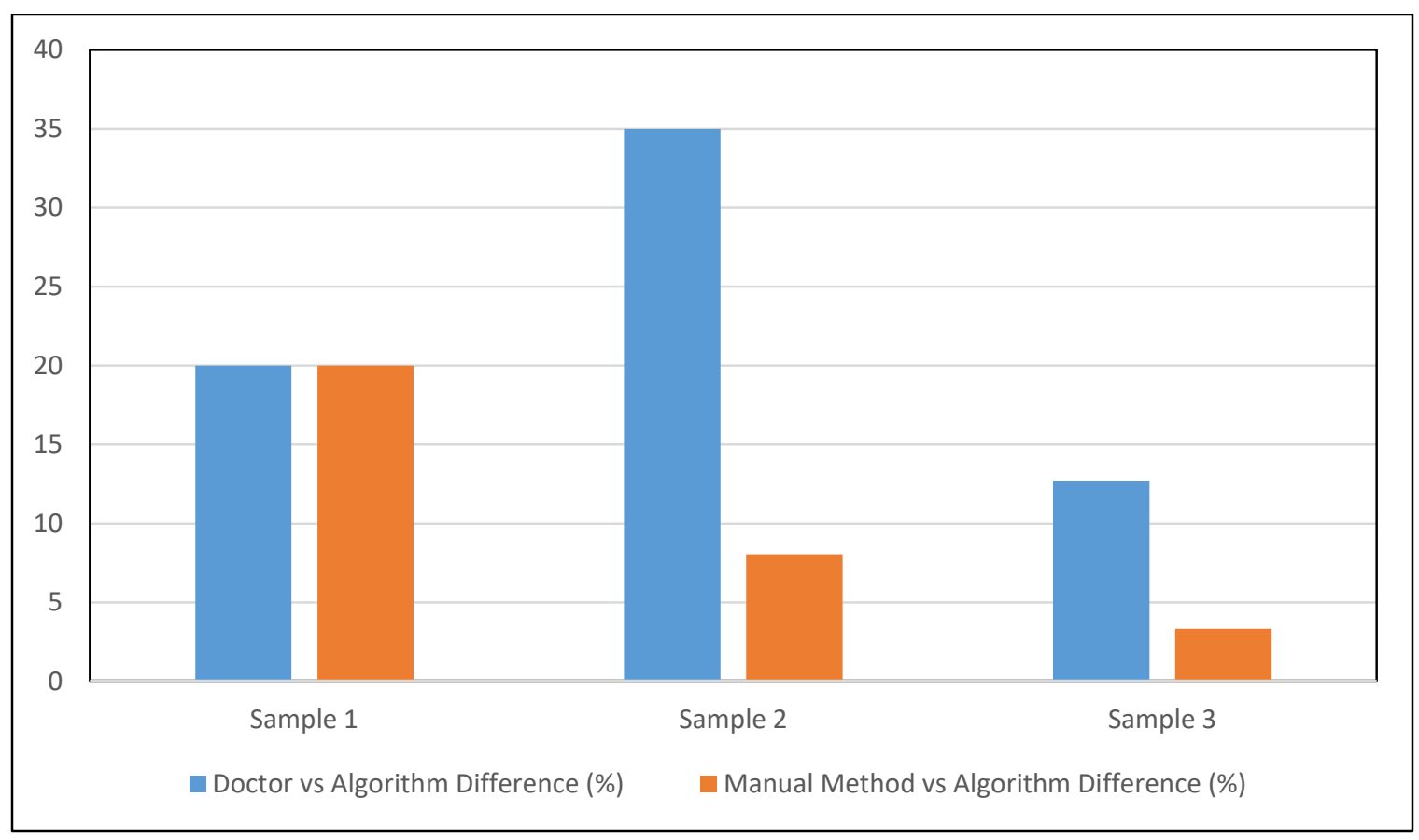

Fig 4.2.2: Comparing the Percentages of Errors Using Specified Methods among the Proposed Method and Existing Methods

\subsection{Accuracy of Otsu Threshholding Value}

While segmenting the coronary artery ostu thresholding methods has been applied with high and low band pass. These will separate connected arteries and non-connected parts. Area or total connected pixels are measured with trial and error method. Based on that result, accuracy of thresholding values can be gained. 
Table 4: Accuracy test result of Ostu Thresholding value

\begin{tabular}{|c|c|c|}
\hline High Band Pass & Low Band Pass & Accuracy \% \\
\hline 120 & 230 & 35.48 \\
\hline 135 & 244 & 41.11 \\
\hline 141 & 255 & 98.75 \\
\hline 165 & 210 & 16.74 \\
\hline 170 & 225 & 12.05 \\
\hline
\end{tabular}

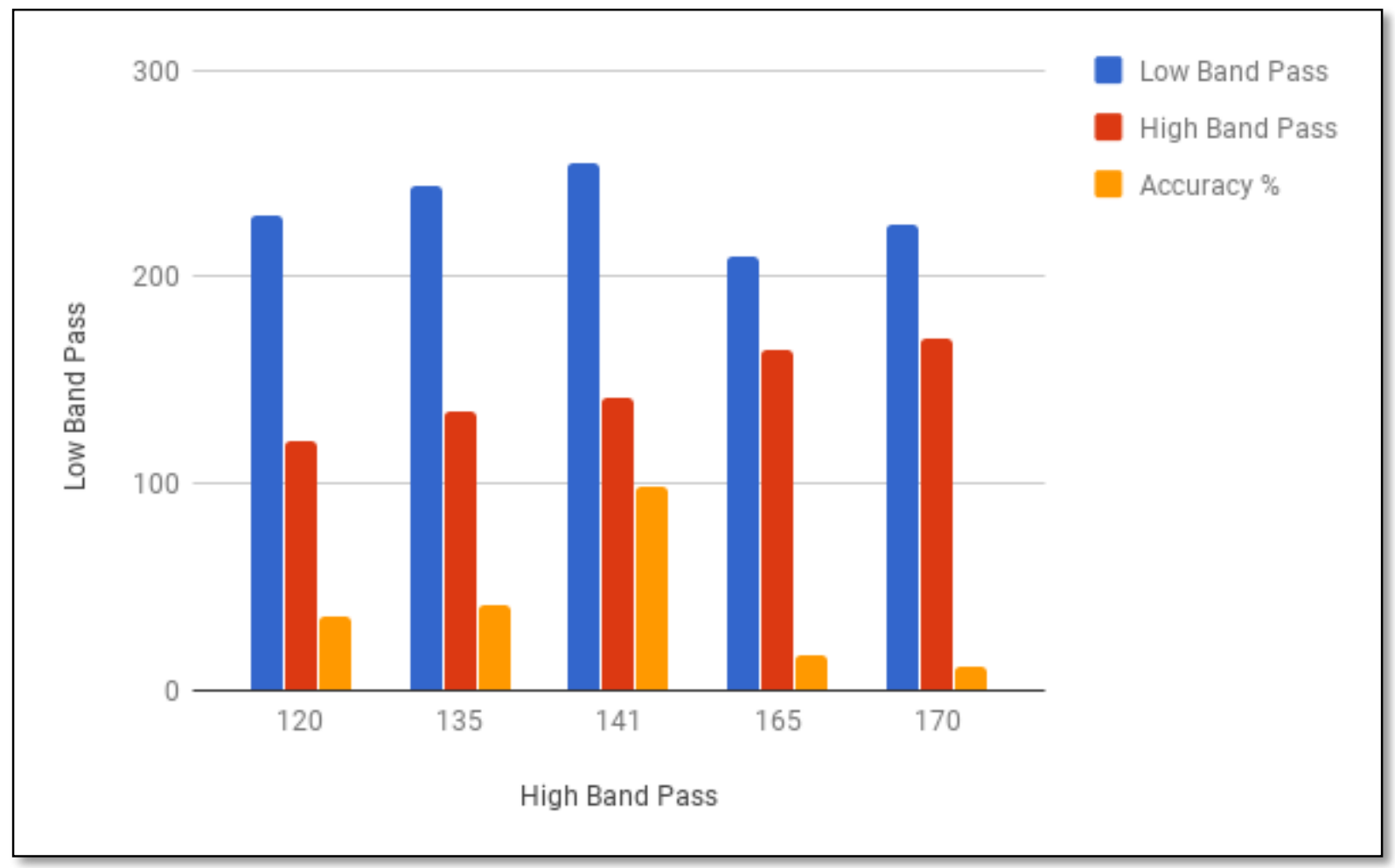

Fig. 4.3.1: Accuracy test result of Ostu Thresholding value

\subsection{Dataset of Perimeter Pixel Coordinates}

The system detects the perimeter of each artery of each sample. Based on the pixel coordinates the proposed algorithm is executed. Here some contents of dataset have been shown (Figure: 4.4.1 - 4.4.3). 


\begin{tabular}{|c|c|c|c|c|c|c|c|c|c|c|c|c|c|c|c|}
\hline \multicolumn{2}{|c|}{ Current Folder } & & \multicolumn{5}{|c|}{$\triangle$ Editor -yes.m } & & rent Folder & & (1) & DEdI & es.m. & & \\
\hline & Name & & & bo & $\operatorname{ary} x$ & & & [ & Name & & & $1] \sqrt{b}$ & ary $x$ & & \\
\hline$\Phi$ & \#\#copy this & & $\wedge$ & $\boxplus 352$ & double & & & 田 & \#\#copy this & & $\wedge$ & $\boxplus 35$ & touble & & \\
\hline $\begin{array}{l}\text { 田 } \\
\text { 开 }\end{array}$ & $\begin{array}{l}\text { appdata } \\
\text { bin }\end{array}$ & & & & 1 & 2 & 3 & 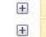 & $\begin{array}{l}\text { appdata } \\
\text { bin }\end{array}$ & & & & & 2 & 3 \\
\hline$\oplus$ & bugreport & & & 1 & 1158 & 1010 & & $\boxplus$ & bugreport & & & 160 & 1045 & 1090 & \\
\hline$\boxplus$ & client & & t & 2 & 1157 & 1011 & & 田 & client & & & 161 & 1044 & 1090 & \\
\hline$\boxplus$ & etc & & - & 3 & 1156 & 1011 & & 田 & etc & & 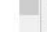 & 162 & 1043 & 1090 & \\
\hline 由 & examples & & & 4 & 1155 & 1011 & & 田 & examples & & & 163 & 1042 & 1090 & \\
\hline$\underset{⿴ 囗 十 力}{\oplus}$ & $\begin{array}{l}\text { extern } \\
\text { help }\end{array}$ & & & 5 & 1154 & 1012 & & $\stackrel{\oplus}{\oplus}$ & $\begin{array}{l}\text { extern } \\
\text { help }\end{array}$ & & & 164 & 1041 & 1090 & \\
\hline 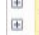 & $\begin{array}{l}\text { help } \\
\text { java }\end{array}$ & & & 6 & 1153 & 1013 & & 田 & java & & 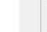 & 165 & 1040 & 1090 & \\
\hline 田 & lib & & & 7 & 1152 & 1013 & & 田 & lib & & 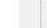 & 166 & 1039 & 1090 & \\
\hline$\oplus$ & licenses & & & 8 & 1151 & 1014 & & 田 & licenses & & & 167 & 1038 & 1091 & \\
\hline$\oplus$ & $\operatorname{man}$ & & & 9 & 1150 & 1015 & & 田 & $\operatorname{man}$ & & & 168 & 1037 & 1091 & \\
\hline$\boxplus$ & $\begin{array}{l}\text { mer } \\
\text { notebook }\end{array}$ & & $v$ & 10 & 1149 & 1016 & & 田 & $\begin{array}{l}\text { mcr } \\
\text { notebook }\end{array}$ & & $\checkmark$ & 169 & 1036 & 1092 & \\
\hline Deta & & & $\hat{\imath}$ & 11 & 1149 & 1017 & & $\overline{\text { Deta }}$ & & & $\hat{\imath}$ & 170 & 1035 & 1093 & \\
\hline Dera & & & & 12 & 1148 & 1018 & & wetar & & & (n) & 171 & 1034 & 1094 & \\
\hline Wo & kspace & & ( ) & 13 & 1148 & 1019 & & Wor & rkspace & & () & 172 & 1033 & 1094 & \\
\hline Nar & e - & Value & & 14 & 1147 & 1020 & & Nan & me - & Value & (a) & 173 & 1032 & 1095 & \\
\hline 田。 & & $1769 \times 2939$ vints & $\wedge$ & 15 & 1147 & 1021 & & 思 & & $1769 \times 2939$ uints & $\wedge$ & 174 & 1031 & 1096 & \\
\hline 畐。 & & $4.4893 \mathrm{e}+04$ & & 16 & 1147 & 1022 & & 思 & & $4.4893 e+04$ & & 175 & 1030 & 1096 & \\
\hline 19 & rtery_TEST & $1 \times 1$ cell & & 17 & 1147 & 1023 & & (1) $\mathrm{A}$ & Artery_TEST & $1 \times 1$ cell & & 176 & 1029 & 1097 & \\
\hline$M$ & & $\begin{array}{l}1769 \times 2939 \text { logical } \\
3523 \times 2 \text { double }\end{array}$ & & 18 & 1146 & 1024 & & $\checkmark B$ & 1 & $\begin{array}{l}1769 \times 2939 \text { logical } \\
3523 \times 2 \text { double }\end{array}$ & & 177 & 1028 & 1097 & \\
\hline$\nabla \mathrm{B}$ & $\begin{array}{l}\text { oundary } \\
\text { W }\end{array}$ & $\begin{array}{l}3523 \times 2 \text { double } \\
1769 \times 2939 \text { logical }\end{array}$ & & 19 & 1146 & 1025 & & $\Delta \mathrm{B}$ & & $\begin{array}{l}3523 \times 2 \text { double } \\
1769 \times 2939 \text { logical }\end{array}$ & & 178 & 1027 & 1098 & \\
\hline Ba & & $1769 \times 2939$ logical & 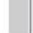 & 20 & 1146 & 1026 & & $\nabla \mathrm{B}$ & & $1769 \times 2939$ logical & 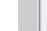 & 179 & 1026 & 1099 & \\
\hline$\checkmark B$ & & $1769 \times 2939$ logical & & $<$ & & & & $\mathrm{B}$ & W7 & $1769 \times 2939$ logical & & $<$ & & & \\
\hline 畺。 & & $1769 \times 2939 \times 3$ uint8 & $\checkmark$ & Comm & Window & & & 思in & & $1769 \times 2939 \times 3$ uint8 & $\checkmark$ & Comm & Window & & \\
\hline Curr & int Folder & & (1) & $\square$ Edit & yes.m & & & Curre & int Folder & & (1) & $\triangle \mathrm{Ed}$ & yes.m & & \\
\hline ए & Name & & 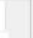 & $1 \sqrt{b c}$ & ary $x$ & & & 口 & Name & & 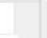 & $11 \sqrt{b}$ & $\operatorname{ary} x$ & & \\
\hline 田 & \#\#copy this & & $\hat{\imath}$ & 田 352 & double & & & 田 & \#copy this & & ค & 田35 & double & & \\
\hline $\begin{array}{l}\text { 田 } \\
\text { 甲 }\end{array}$ & $\begin{array}{l}\text { appdata } \\
\text { bin }\end{array}$ & & & & 1 & 2 & 3 & 田 & $\begin{array}{l}\text { appdata } \\
\text { bin }\end{array}$ & & & & & 2 & 3 \\
\hline (4) & bugreport & & & 1086 & 668 & 1744 & & \pm & bugreport & & & 3241 & 1034 & 1201 & \\
\hline (由) & client & & 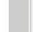 & 1087 & 669 & 1744 & & 田 & client & & & 3242 & 1034 & 1200 & \\
\hline (由) & etc & & 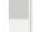 & 1088 & 670 & 1745 & & 田 & etc & & 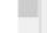 & 3243 & 1034 & 1199 & \\
\hline 田 & examples & & 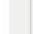 & 1089 & 671 & 1745 & & $\boxplus$ & examples & & 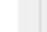 & 3244 & 1033 & 1198 & \\
\hline 田 & $\begin{array}{l}\text { extern } \\
\text { help }\end{array}$ & & 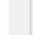 & 1090 & 672 & 1745 & & 田 & extern & & 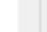 & 3245 & 1033 & 1197 & \\
\hline (t) & $\begin{array}{l}\text { help } \\
\text { java }\end{array}$ & & & 1091 & 673 & 1745 & & 田 & $\begin{array}{l}\text { help } \\
\text { java }\end{array}$ & & 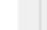 & 3246 & 1033 & 1196 & \\
\hline 田 & lib & & 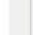 & 1092 & 674 & 1746 & & $\boxplus$ & lib & & ( & 3247 & 1033 & 1195 & \\
\hline 田 & licenses & & 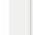 & 1093 & 675 & 1747 & & 田 & licenses & & ( & 3248 & 1033 & 1194 & \\
\hline (4) & man & & 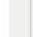 & 1094 & 676 & 1747 & & $\boxplus$ & $\operatorname{man}$ & & 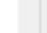 & 3249 & 1034 & 1193 & \\
\hline 田 & $\begin{array}{l}\mathrm{mcr} \\
\text { notebook }\end{array}$ & & $\checkmark$ & 1095 & 677 & 1747 & & $\boxplus$ & $\begin{array}{l}\mathrm{mcr} \\
\text { notebook }\end{array}$ & & $\checkmark$ & 3250 & 1034 & 1192 & \\
\hline Detai & & & $\hat{\wedge}$ & 1096 & 678 & 1748 & & Details & notebook & & $\hat{\imath}$ & 3251 & 1034 & 1191 & \\
\hline Worl & space & & $(7)$ & 1097 & 679 & 1748 & & & & & a & 3252 & 1034 & 1190 & \\
\hline & & & & 1098 & 680 & 1749 & & Works & space & & (1) & 3253 & 1034 & 1189 & \\
\hline $\mathrm{Nam}$ & & Value & & 1099 & 681 & $\begin{array}{l}1749 \\
1750\end{array}$ & & Name & & Value & 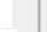 & 3254 & 1034 & 1188 & \\
\hline 田 & & 1769:2939 uint8 & $\wedge$ & 1100 & 682 & $\begin{array}{l}1750 \\
1751\end{array}$ & & 男a & & $1769 \times 2939$ uint8 & ค & 3255 & 1034 & 1187 & \\
\hline $\begin{array}{ll}\text { ar } \\
\text { (1) }\end{array}$ & stery TEST & $\begin{array}{l}4.4893 \mathrm{e}+04 \\
1 \times 7 \mathrm{cell}\end{array}$ & & 1101 & 683 & 1751 & & 思 ans & & $4.4893 e+04$ & & 3256 & 1034 & 1186 & \\
\hline$\sim B$ & tery_TEST & $\begin{array}{l}1 \times 1 \text { cell } \\
1769 \times 2939 \text { logical }\end{array}$ & & 1102 & 684 & $\begin{array}{l}1751 \\
175\end{array}$ & & (1) Art & tery_TEST & $1 \times 1$ cell & & 3257 & 1034 & 1185 & \\
\hline Bbc & undary & $3523 \times 2$ double & & 1103 & $\begin{array}{l}685 \\
686\end{array}$ & $\begin{array}{l}1752 \\
1753\end{array}$ & & B1 & undary & $\begin{array}{l}1769 \times 2939 \text { logical } \\
3523 \times 2 \text { double }\end{array}$ & & 3258 & 1033 & 1184 & \\
\hline$\checkmark B$ & & $1769 \times 2939$ logical & & $\frac{1104}{1105}$ & 6887 & $\begin{array}{l}1735 \\
1753\end{array}$ & & $\checkmark B W$ & & $1769 \times 2939$ logical & & 3259 & 1033 & 1183 & \\
\hline B & & $1769 \times 2939$ logical & & , & & & & $\triangle B W$ & & $1769 \times 2939$ logical & 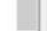 & 3260 & 1032 & 1182 & \\
\hline$\checkmark B$ & & $\begin{array}{l}1769 \times 2939 \text { logical } \\
1769 \times 2939 \times 3 \text { vint } 8\end{array}$ & & < & Window & & & $\triangle B W$ & & $1769 \times 2939$ logical & & 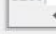 & & & \\
\hline Bin & & $1769 \times 2939 \times 3$ uint8 & $v$ & Comm & Window & & & 思img & & $1769 \times 2939 \times 3$ uint8 & $\checkmark$ & Comn & Window & & \\
\hline Cur & rent Folder & & $\odot$ & Z Edir & yes.m & & & Cur & rent Folder & & (1) & $\nabla$ Edi & es.m & & \\
\hline ( & Name & & 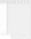 & $1 \sqrt{b c}$ & $\operatorname{lary} x$ & & & 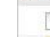 & Name & & 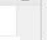 & $1]$ & ary $\times$ & & \\
\hline 田 & \#\#copy this & & ค & $\boxplus 352$ & double & & & $\boxplus$ & \#\#copy this & & 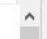 & $\boxplus 35$ & touble & & \\
\hline $\begin{array}{l} \pm \\
\Psi\end{array}$ & $\begin{array}{l}\text { appdata } \\
\text { bin }\end{array}$ & & & & 1 & 2 & 3 & $\begin{array}{l} \pm \\
\pm \\
\end{array}$ & $\begin{array}{l}\text { appdata } \\
\text { bin }\end{array}$ & & & & & 2 & 3 \\
\hline 田 & bugreport & & 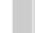 & 1209 & 791 & 1784 & & 由 & bugreport & & 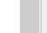 & 3505 & 1164 & 1023 & \\
\hline 田 & client & & 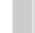 & 1210 & 792 & 1784 & & 田 & client & & . & 3506 & 1164 & 1022 & \\
\hline$\Phi$ & etc & & L & 1211 & 793 & 1784 & & 田 & etc & & 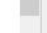 & 3507 & 1165 & 1021 & \\
\hline 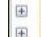 & $\begin{array}{l}\text { examples } \\
\text { extern }\end{array}$ & & & 1212 & 794 & 1784 & & 田 & examples & & 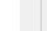 & 3508 & 1165 & 1020 & \\
\hline $\begin{array}{l} \pm \pm \\
\pm\end{array}$ & $\begin{array}{l}\text { extern } \\
\text { help }\end{array}$ & & 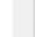 & 1213 & 795 & 1784 & & $\begin{array}{l}\text { 田 } \\
\text { 田 }\end{array}$ & $\begin{array}{l}\text { extern } \\
\text { help }\end{array}$ & & & 3509 & 1165 & 1019 & \\
\hline 田 & java & & & 1214 & 796 & 1784 & & 田 & java & & 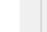 & 3510 & 1165 & 1018 & \\
\hline 田 & lib & & 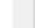 & 1215 & 797 & 1784 & & 由 & lib & & 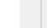 & 3511 & 1166 & 1017 & \\
\hline 田 & licenses & & & 1216 & 798 & 1784 & & 田 & licenses & & & 3512 & 1166 & 1016 & \\
\hline 田 & $\operatorname{man}$ & & & 1217 & 799 & 1785 & & $\Phi$ & man & & 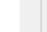 & 3513 & 1165 & 1015 & \\
\hline | & $\begin{array}{l}\mathrm{mcr} \\
\text { notebook }\end{array}$ & & $v$ & 1218 & 800 & 1785 & & 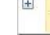 & $\begin{array}{l}\text { mcr } \\
\text { notebook }\end{array}$ & & $\checkmark$ & 3514 & 1165 & 1014 & \\
\hline Det: & & & $\hat{\wedge}$ & 1219 & 801 & 1785 & & $\overline{\text { Deta }}$ & & & ^ & 3515 & 1165 & 1013 & \\
\hline & & & & 1220 & 802 & 1786 & & & & & & 3516 & 1164 & 1012 & \\
\hline & kspace & & (c) & 1221 & 803 & 1786 & & & rkspace & & ()) & 3517 & 1164 & 1011 & \\
\hline & ne - & Value & & 1222 & 804 & 1786 & & Nar & ne - & Value & & 3518 & 1163 & 1010 & \\
\hline$\boxplus$ & & $1769 \times 2939$ uint8 & $\wedge$ & 1223 & 805 & 1787 & & 田。 & & $1769 \times 2939$ uint8 & $\wedge$ & 3519 & 1162 & 1010 & \\
\hline 田 & & $4.4893 \mathrm{e}+04$ & & 1224 & 806 & 1788 & & 思 & ins & $4.4893 e+04$ & & 3520 & 1161 & 1010 & \\
\hline & intery_TEST & $1 \times 1$ cell & & 1225 & 807 & 1788 & & & Artery_TEST & $\begin{array}{l}1 \times 1 \text { cell } \\
17602039 / 20 \text { ised }\end{array}$ & & 3521 & 1160 & 1010 & \\
\hline$\checkmark$ & 1 & $\begin{array}{l}1769 \times 2939 \text { logical } \\
3523 \times 2 \text { double }\end{array}$ & & 1226 & 808 & 1788 & & $\checkmark \mathrm{B}$ & poundary & $\begin{array}{l}\text { 1769x2939 logical } \\
3523 \times 2 \text { double }\end{array}$ & & 3522 & 1159 & 1010 & \\
\hline 吾 & $\begin{array}{l}\text { oundary } \\
\text { W }\end{array}$ & $1769 \times 2939$ logical & & 1227 & 809 & 1788 & & $\checkmark B$ & & 1769x2939 logical & & 3523 & 1158 & 1010 & \\
\hline$\checkmark$ & & $1769 \times 2939$ logical & & 1228 & 810 & 1788 & & $\sqrt{V B}$ & WW1 & $1769 \times 2939$ logical & & 3524 & & & \\
\hline v & & $1769 \times 2939$ logical & 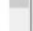 & s & & & & $\sqrt{B}$ & & $1769 \times 2939$ logical & & \begin{tabular}{|c} 
\\
\end{tabular} & & & \\
\hline 画 & & $1769 \times 2939 \times 3$ uint 8 & $v$ & Comm & Window & & & 思i & & $1769 \times 2939 \times 3$ uint8 & $\checkmark$ & Comn & Window & & \\
\hline
\end{tabular}

Fig 4.4.1: Pixel Coordinates for Sample 1. 


\begin{tabular}{|c|c|c|c|c|c|c|c|c|c|c|c|c|c|c|c|}
\hline \multicolumn{2}{|c|}{ Current Folder } & & (†) & & premi.m & & & \multicolumn{2}{|c|}{ Current Folder } & & (7) & \multicolumn{4}{|c|}{2 Editor-premi.m } \\
\hline \multicolumn{3}{|c|}{ Name } & \multirow{3}{*}{$\hat{\imath}$} & \multicolumn{4}{|c|}{$1 \sqrt{\text { boundary } x}$} & \multicolumn{4}{|c|}{ Name } & \multicolumn{4}{|c|}{ boundary $x$} \\
\hline (由) & \multicolumn{2}{|l|}{ "scopy this } & & 田 & double & & & $\boxplus$ & \multirow{2}{*}{\multicolumn{2}{|c|}{$\begin{array}{l}\text { E*copy this } \\
\text { appdata }\end{array}$}} & \multirow[t]{2}{*}{ A } & 田 & double & & \\
\hline 国 & $\begin{array}{l}\text { appdata } \\
\text { bin }\end{array}$ & & & & 1 & 2 & 3 & $\Phi$ & & & & & 1 & 2 & 3 \\
\hline 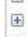 & bugreport & & & 1 & 675 & 1320 & & 田 & bugreport & & & 55 & 722 & 1349 & \\
\hline$\boxplus$ & client & & - & 2 & 674 & 1321 & & $\boxplus$ & client & & 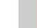 & 56 & 723 & 1349 & \\
\hline$\boxplus$ & etc & & 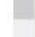 & 3 & 673 & 1322 & & $\boxplus$ & etc & & I & 57 & 724 & 1350 & \\
\hline$\Phi$ & examples & & & 4 & 673 & 1323 & & (17) & examples & & & 58 & 725 & 1350 & \\
\hline 田 & $\begin{array}{l}\text { extern } \\
\text { help }\end{array}$ & & & 5 & 673 & 1324 & & $\left(\begin{array}{ll}|t| \\
(7)\end{array}\right.$ & $\begin{array}{l}\text { extern } \\
\text { help }\end{array}$ & & & 59 & 726 & 1351 & \\
\hline 田 & java & & & 6 & 673 & 1325 & & $\pi$ & java & & & 60 & 727 & 1352 & \\
\hline 田 & lib & & & 7 & 674 & 1326 & & $\oplus$ & lib & & & 61 & 728 & 1352 & \\
\hline 田 & licenses & & & 8 & 675 & 1327 & & $\boxplus$ & licenses & & & 62 & 729 & 1353 & \\
\hline$\boxplus$ & $\operatorname{man}$ & & & 9 & 676 & 1327 & & $\boxplus$ & man & & & 63 & 730 & 1353 & \\
\hline 由 & $\begin{array}{l}\text { mcr } \\
\text { notebook }\end{array}$ & & $\checkmark$ & 10 & 677 & 1328 & & $\Phi$ & & & $\checkmark$ & 64 & 731 & 1354 & \\
\hline & & & $\wedge$ & 11 & 678 & 1329 & & Det & notebook & & $\hat{\imath}$ & 65 & 732 & 1354 & \\
\hline & & & & 12 & 679 & 1329 & & Dete & & & & 66 & 733 & 1355 & \\
\hline & ispace & & (1) & 13 & 680 & 1330 & & & espace & & () & 67 & 734 & 1355 & \\
\hline & & Value & & 14 & 681 & 1330 & & Nar & & Value & & 68 & 735 & 1356 & \\
\hline 需 & $\pi$ & $2100 \times 2100 \times 3$ uint8 & & & & & & $\boxplus$ & & $2100 \times 2100 \times 3$ uint8 & & & & & \\
\hline & tery_TEST & $\begin{array}{l}2 \times 1 \text { cell } \\
\text { f21v2 Anuhle }\end{array}$ & & Con & d Window & & & 苗 & $\begin{array}{l}\text { tery_TEST } \\
\text { pundary }\end{array}$ & $\begin{array}{l}2 \times 1 \text { cell } \\
631 \times 2 \text { double }\end{array}$ & & & d Window & & \\
\hline & ent Folder & & (c) & ¿E & premim & & & $\pi F$ & muqsu & ए31.5 पणmplo & & cow & Miuqom & & \\
\hline & Name & & 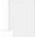 & 15 & dary $x$ & & & 苗 & ItCI & $5100 \times 5100 \times 3$ nivu 88 & & 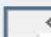 & & & \\
\hline Ф & Izcopy this & & ^ & 田6 & double & & & $4^{94}$ & & $\wedge$ भाกต & & $53 e$ & 203 & 1305 & \\
\hline$\Phi$ & $\begin{array}{l}\text { appdata } \\
\text { bin }\end{array}$ & & t & & 1 & 2 & 3 & MO & absce & & (c) & 532 & 205 & 1321 & \\
\hline 田 & bugreport & & . & 172 & 839 & 1381 & & & & & 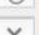 & 534 & 201 & 1301 & \\
\hline 田 & client & & 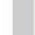 & 173 & 840 & 1381 & & DEt9 & yotepook & & 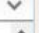 & 533 & 200 & 1301 & \\
\hline$\Phi$ & etc & & 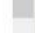 & 174 & 841 & 1382 & & & $\begin{array}{l}\text { voffpook } \\
\text { wei }\end{array}$ & & $\wedge$ & 535 & $8 \partial \partial$ & 1301 & \\
\hline$\Phi$ & examples & & 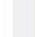 & 175 & 842 & 1382 & & 田 & wgu & & & 53.1 & 828 & 1300 & \\
\hline (t) & $\begin{array}{l}\text { extern } \\
\text { help }\end{array}$ & & 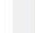 & 176 & 843 & 1383 & & 田 & HiceUzez & & 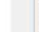 & 530 & 821 & 1330 & \\
\hline$\stackrel{\dagger}{\oplus}$ & $\begin{array}{l}\text { help } \\
\text { java }\end{array}$ & & 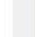 & 177 & 844 & 1383 & & $\boxplus$ & IIP & & & 550 & $8 \partial e$ & 1300 & \\
\hline$\Phi$ & lib & & 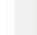 & 178 & 845 & 1383 & & 甲 & lons & & & 558 & 802 & 1320 & \\
\hline 田 & licenses & & & 179 & 846 & 1384 & & 田 & $\mu \mathrm{qb}$ & & & 551 & $88 \mathrm{t}$ & 1300 & \\
\hline 田 & man & & & 180 & 847 & 1384 & & $\frac{4}{4}$ & 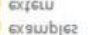 & & . & sse & 803 & 1300 & \\
\hline (1) & & & & 181 & 848 & 1385 & & 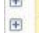 & Eदc & & 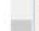 & 552 & 805 & 1300 & \\
\hline & notebook & & $\checkmark$ & 182 & 849 & 1386 & & 甲 & cHeuf & & ( & $5 s t$ & 801 & 1300 & \\
\hline & & & $\wedge$ & 183 & 850 & 1386 & & $\boxplus$ & pnàıbou & & & 553 & 800 & 1320 & \\
\hline & kspace & & (1) & 184 & 851 & 1387 & & 由 & piu & & & & - & 5 & 3 \\
\hline & e - & Value & & 185 & 852 & 1387 & & 田 & $\begin{array}{l}\text { 9bbq9is } \\
= \pm \operatorname{cob} \lambda \text { qp!? }\end{array}$ & & $\checkmark$ & 田e: & onple & & \\
\hline 囸 & & $2100 \times 2100 \times 3$ vint8 & & & & & & [ & ияш6 & & & & $\operatorname{si\lambda } x \int$ & & \\
\hline & $\begin{array}{l}\text { itery_TEST } \\
\text { oundary }\end{array}$ & $\begin{array}{l}2 \times 1 \text { cell } \\
631 \times 2 \text { douhle }\end{array}$ & & Con & Window & & & crum & Uf $t$ 잍 & & (2) & $\triangle E^{\circ}$ & कเตய!'พ & & \\
\hline & ent Folder & & (־) & $\nabla \mathrm{E}$ & premi.m. & & & & ent Folder & & (1) & $D \mathrm{Eg}$ & premi.m & & \\
\hline & Name & & 1 & $1 \sqrt{1}$ & tary $x$ & & & t. & Name & & & 1 & ary $x$ & & \\
\hline$\boxplus$ & Etcopy this & & ^ & 田6 & touble & & & $\boxplus$ & Etcopy this & & ^ & 田6 & ouble & & \\
\hline$\Phi$ & $\begin{array}{l}\text { appdata } \\
\text { bin }\end{array}$ & & & & & 2 & 3 & 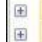 & $\begin{array}{l}\text { appdata } \\
\text { bin }\end{array}$ & & & & & 2 & 3 \\
\hline 田 & bugreport & & & 271 & 938 & 1390 & & $\boxplus$ & bugreport & & & 328 & 978 & 1356 & \\
\hline 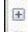 & client & & 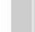 & 272 & 939 & 1390 & & 田 & client & & & 329 & 977 & 1356 & \\
\hline$\Phi$ & etc & & 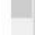 & 273 & 940 & 1390 & & $\boxplus$ & etc & & 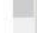 & 330 & 976 & 1356 & \\
\hline Ф & examples & & & 274 & 941 & 1390 & & 田 & examples & & 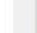 & 331 & 975 & 1356 & \\
\hline 由 & $\begin{array}{l}\text { extern } \\
\text { help }\end{array}$ & & 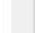 & 275 & 942 & 1389 & & $\begin{array}{l}\oplus \\
\oplus\end{array}$ & $\begin{array}{l}\text { extern } \\
\text { help }\end{array}$ & & 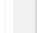 & 332 & 974 & 1356 & \\
\hline$\Phi$ & $\begin{array}{l}\text { help } \\
\text { java }\end{array}$ & & & 276 & 943 & 1389 & & $\oplus$ & $\begin{array}{l}\text { help } \\
\text { java }\end{array}$ & & 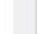 & 333 & 973 & 1356 & \\
\hline 田 & lib & & & 277 & 944 & 1389 & & 田 & lib & & & 334 & 972 & 1356 & \\
\hline 田 & licenses & & 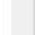 & 278 & 945 & 1389 & & $\Phi$ & licenses & & & 335 & 971 & 1356 & \\
\hline 田 & $\operatorname{man}$ & & 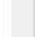 & 279 & 946 & 1389 & & $\boxplus$ & man & & 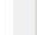 & 336 & 970 & 1356 & \\
\hline$\Phi$ & $\begin{array}{l}\mathrm{mcr} \\
\text { notebook }\end{array}$ & & $v$ & 280 & 947 & 1388 & & $\Phi$ & $\mathrm{mcr}$ & & $\checkmark$ & 337 & 969 & 1356 & \\
\hline & is & & $\hat{\wedge}$ & 281 & 948 & 1388 & & Det: & notebook & & $\hat{\imath}$ & 338 & 968 & 1357 & \\
\hline & & & 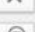 & 282 & 949 & 1388 & & & & & $\hat{n}$ & 339 & 967 & 1357 & \\
\hline & sppace & & ( & 283 & 950 & 1387 & & & kspace & & (1) & 340 & 966 & 1357 & \\
\hline & e- & Value & & 284 & 951 & 1387 & & & e - & Value & & 341 & 965 & 1358 & \\
\hline 䟧 & & $2100 \times 2100 \times 3$ uint8 & & \begin{tabular}{|c} 
\\
\end{tabular} & & & & $\boxplus$ & & $2100 \times 2100 \times 3$ uint8 & & 3 & & & \\
\hline & $\begin{array}{l}\text { rtery_TEST } \\
\text { oundary }\end{array}$ & $\begin{array}{l}2 \times 1 \text { cell } \\
631 \times 2 \text { double }\end{array}$ & & Com & Window & & & & $\begin{array}{l}\text { rtery_TEST } \\
\text { oundary }\end{array}$ & $\begin{array}{l}2 \times 1 \text { cell } \\
631 \times 2 \text { double }\end{array}$ & & Com & Window & & \\
\hline
\end{tabular}

Fig 4.4.2: Pixel Coordinates for Sample 2. 


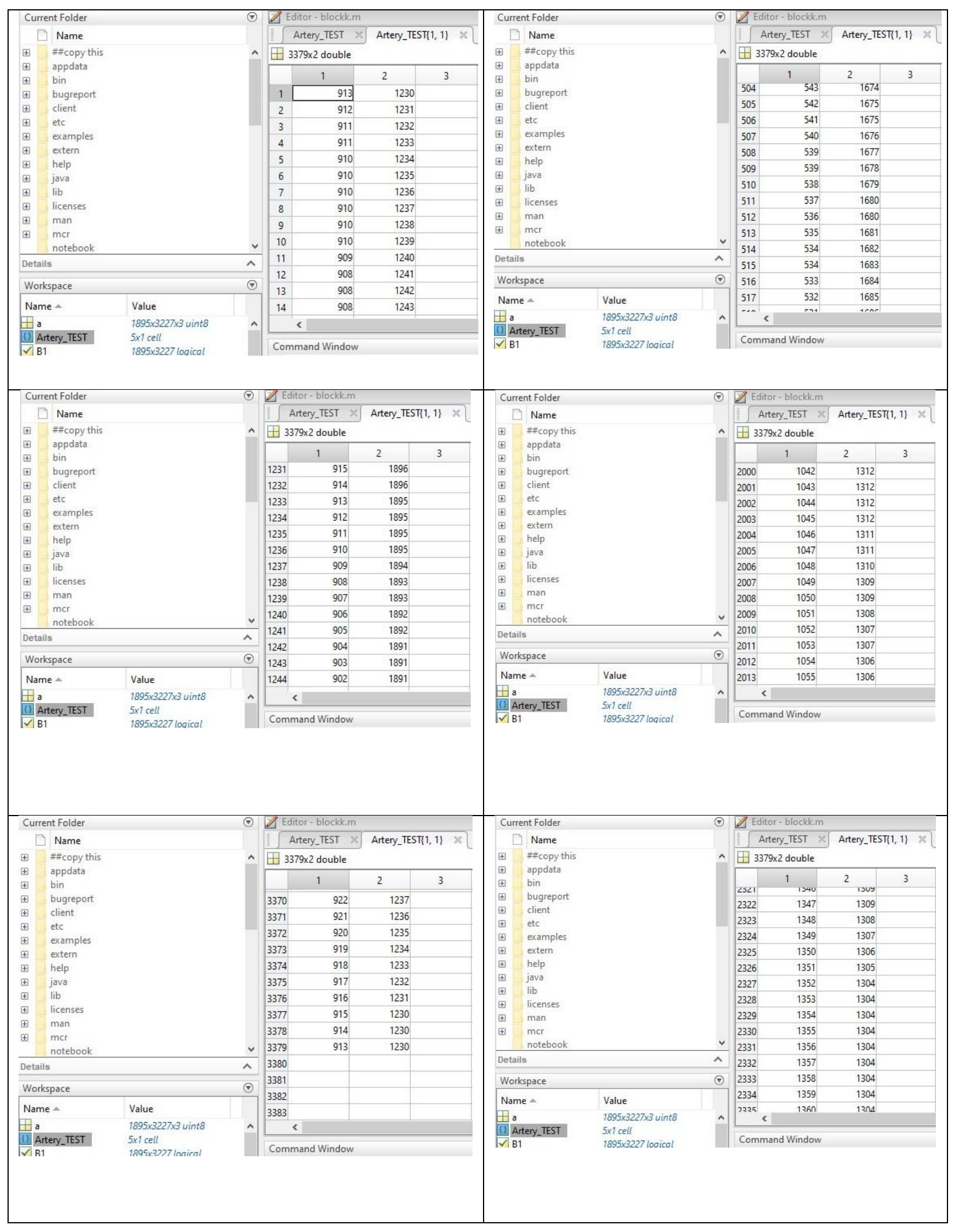

Fig 4.4.3: Pixel Coordinates for Sample 3. 


\subsection{D Visualization}

Finally, using the estimated gradient and shading the output 3D models are generated.
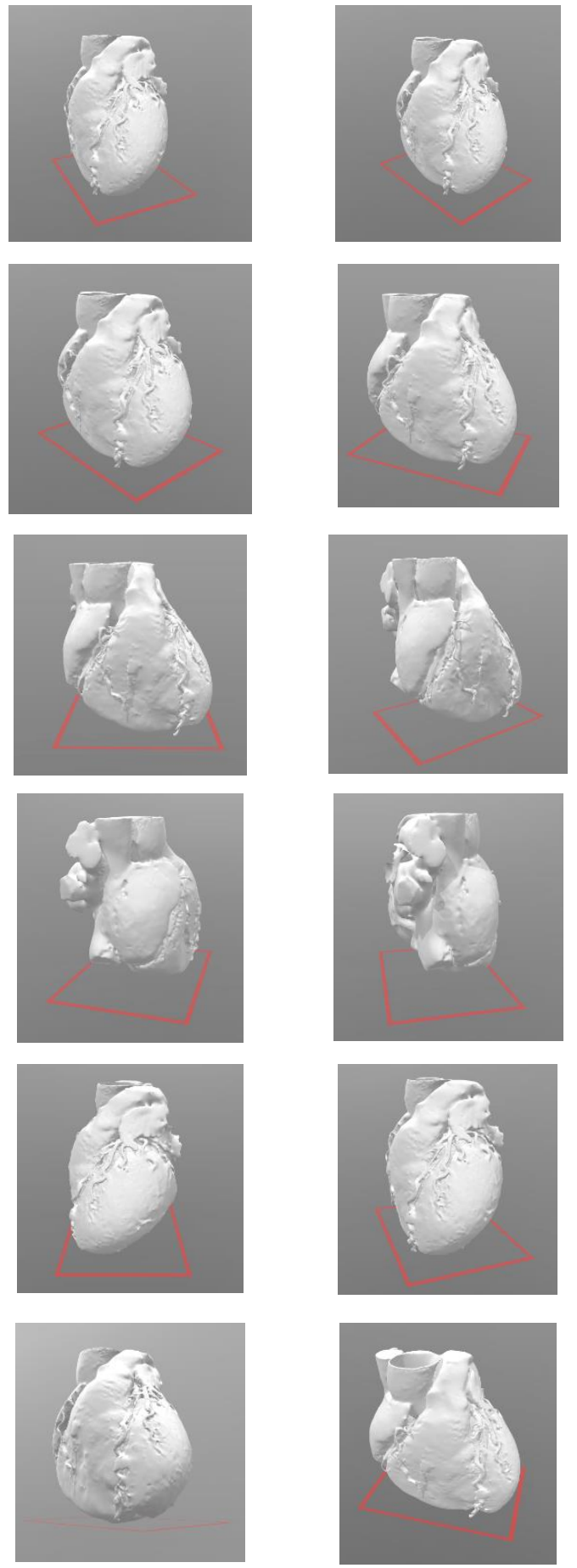

Fig. 4.5.1: 3D Model of Heart Using Volume Rendering 

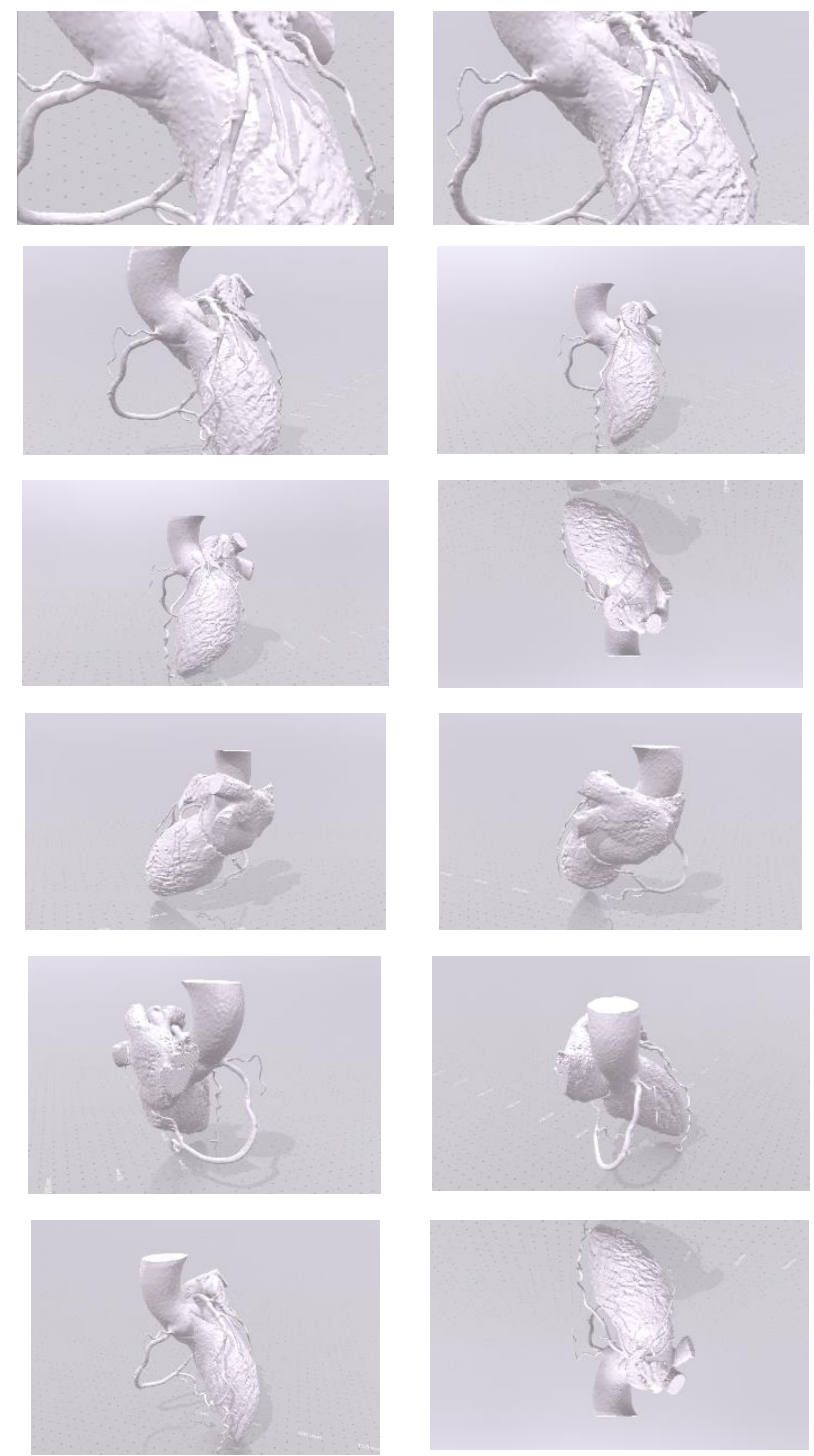

Fig. 4.5.2: 3D Model of Coronary Arteries Using Volume Rendering 


\section{Chapter V \\ Conclusion and Future Works}

\subsection{Concluding Remark}

In this research, all the methods that were used have been selected using trial-and-error technique. Different methods were used on every steps and the method to be selected was chosen based on the perfection of result on our input.

All the discussion and evaluation that has been used in this paper was carried out through huge dataset in order to ensure the reliability.

Lastly, it can be said that, the whole purpose of this research is to create an autonomous system of an existing system. The already existing system relies on the evaluation of a doctor which can vary depending on a number of factors. However, since our newly created system doesn't rely on human judgment at all, its generated report won't differ for the same input. Again, in order to evaluate the perfection of the proposed system, the results were shown to a number of doctors. The doctor's report and the report developed by our system has approximately an $80 \%$ match.

\subsection{Future Works}

This research has come up with a novel approach to detect the amount of heart blockage from CTA images.

In distant future the system will be tested for efficiency and error process with large number of data set from patient with different heart conditions. Also a professional and user friendly Graphical User Interface will be created. Last but not the least, the execution of GPU Parallel Processing will be ensured. 


\section{References}

[1] A.Farhad. 2014 "K-means clustering based angiographic image analysis to measure coronary stenosis", Eastern Mediterranean University.

[2] S. Agrawal, "Automated Segmentation of Cardiac Stenosis and Mathematical Modeling of Myocardial Blood Flow for Early Detection of Heart Attack Using Advanced Imaging Techniques", IOSR Journal of Computer Engineering, vol. 16, no. 6, pp. 41-47, 2014.

[3] R.Shahzad, S.Michiel, F.B. Goncalves, C.T.Metz, T.Hui, T.V.Walsum, A.Moelker, L.J.Vliet, \& W.J.Niessen. "Automatic detection of calcified lesions in the descending aorta using contrast enhanced CT scans”. Biomedical Imaging (ISBI), 2012 9th IEEE International Symposium on, pp. 250-253, 2012.

[4] A.Wahle, E.Wellnhofer, I.Mugaragu, H.U.Saner, H.Oswald \& E.Fleck, “Assessment of diffuse coronary artery disease by quantitative analysis of coronary morphology based upon 3-D reconstruction from biplane angiograms”. IEEE Transactions on Medical Imaging, vol. 14, no. 2, pp. 230-241, Jun 1995.

[5] P. Nikos, "Geodesic active regions: A new framework to deal with frame partition problems in computer vision.” Journal of Visual Communication and Image Representation, vol. 13, pp. 249$268,2002$.

[6] M.Mazinani, S.D.Qanadli, R.Hosseini, E.T.Dehmeshki , "A 3D Approach for Extraction of the Coronary artery and Quantification of the Stenosis", World Academy of Science, Engineering and Technology International Journal of Biomedical and Biological Engineering, vol. 5, no. 11, 2011.

[7] Y.Hamed, A.Shafie, Z.B.Mustaffa, "An application of K-Nearest Neighbor interpolation on calibrating corrosion measurements collected by two non-destructive techniques", INSPEC Accession Number: 16284509, Kuala Lumpur, Malaysia.

[8] K.S.Reddy \& R.L.Reddy, "Enlargement of Image Based Upon Interpolation Techniques", International Journal of Advanced Research in Computer and Communication Engineering” vol. 2, no. 12, 2013.

[9] G.Deng, L.W.Cahill, “An adaptive Gaussian filter for noise reduction and edge detection”, NSPEC Accession Number: 4923191, San Francisco, CA, USA, 2002. 
[10] P. Soille, Morphological image analysis. Berlin: Springer, 2010, pp. 173-174.

[11] "Converting color to grayscale", Johndcook.com, 2017. [Online]. Available: https://www.johndcook.com/blog/2009/08/24/algorithms-convert-color-grayscale/. [Accessed: 25- Oct- 2017].

[12] Z.Wang \& Z.,Zhang, "Progressive switching median filter for the removal of impulse noise from highly corrupted images", IEEE Transactions on Circuits and Systems II: Analog and Digital Signal Processing, vol. 46, no. 1, 1999.

[13] L.Jianzhuang, L.Wenqing, T.Yupeng, “Automatic thresholding of gray-level pictures using two-dimension Otsu method", Circuits and Systems, 1991. Conference Proceedings, China. International Conference on Shenzhen, INSPEC Accession Number: 4264481, 1991.

[14] Otsu, N., “A Threshold Selection Method from Gray-Level Histograms”, IEEE Transactions on Systems, Man, and Cybernetics, vol. 9, no. 1, pp. 62-66, 1979.

[15] J.Zhang \& J.Hu. "Image Segmentation Based on 2D Otsu Method with Histogram Analysis", Computer Science and Software Engineering, 2008 International Conference on Hubei, China, 2008.

[16] E.R.Nosal, "Flood-fill algorithms used for passive acoustic detection and tracking”, DOI: 10.1109/PASSIVE.2008.4786975,Hyeres, French Riviera, France, 2009.

[17] B.Chai, J.Vass \& X.Zhuang, "Significance-linked connected component analysis for wavelet image coding”, IEEE Transactions on Image Processing, vol. 8, no. 6, 1999.

[18] E.Rakun, M.Andriani \& I.W.Wiprayoga, "Combining depth image and skeleton data from Kinect for recognizing words in the sign system for Indonesian language (SIBI [SistemIsyaratBahasa Indonesia])", Advanced Computer Science and Information Systems (ICACSIS), 2013 International Conference on Bali, Indonesia, 2014.

[19] Suzuki, S. and Abe, K., Topological Structural Analysis of Digitized Binary Images by Border Following. CVGIP 30 1, pp 32-46, 1985.

[20] G.D.Bailey \& C.T.Jhonston, "FPGA implementation of a Single Pass Connected Components Algorithm”, DOI: 10.1109/DELTA.2008.21, Hong Kong, China, 2008. 
[21] "Contour Tracing", Imageprocessingplace.com, 2017. [Online]. Available: http://www.imageprocessingplace.com/downloads_V3/root_downloads/tutorials/contour_tracing _Abeer_George_Ghuneim/index.html. [Accessed: 16- Oct- 2017].

[22] S.Suzuki, K.Abe. "Topological structural analysis of digitized binary images by border following”. Comput. Vis. Graph. Image Proc. 30:32-46. DOI: 10.1016/0734-189X(85)90016-7, 1985.

[23] G.S.S.Krishnan, N.Vijaya, "Algorithm on tracing the boundary of medical images using abstract cellular complex", Machine Vision and Image Processing (MVIP), International Conference on Taipei, Taiwan,04 February 2013,10.1109/MVIP.2012.6428780, 2012.

[24] R.C.Gonzalez \& R.E.Woods, “Digital Image Processing”. NJ,USA:Prentice- Hall,Inc.Upper Saddle River, 2004.

[25] G. Anbarjafari, "Introduction to image processing", Sisu.ut.ee, 2017. [Online]. Available: https://sisu.ut.ee/imageprocessing/book/1. [Accessed: 21- Nov- 2017].

[26] P.I.Aaronson, J.P.T.Ward \& M.J.Connolly. "The Cardiovascular System at a Glance", 4th ed. United Kingdom: Wiley-Blackwell Publication, pp. 10-16, 2013.

[27] Khokhar, "14.structure \& functions of capillaries, venules and veins", Slideshare.net, 2017.

[Online]. Available: https://www.slideshare.net/kashifkhokhar73/14structure-functions-ofcapillaries-venules-and-veins. [Accessed: 25- Oct- 2017].

[28] "Structure and Function of Blood Vessels | Anatomy and Physiology II", Courses.lumenlearning.com, $2017 . \quad$ [Online]. Available: https://courses.lumenlearning.com/ap2/chapter/structure-and-function-of-blood-vessels/.

[Accessed: 25- Sep- 2017].

[29] P.G.Lacroute. "Fast Volume Rendering Using a Shear-Warp Factorization of the Viewing Transformation”. PhD thesis, Stanford University, 1995.

[30] J.F.Blinn. "Light Reflection Functions for Simulation of Clouds and Dusty Surfaces", Computer Graphics, pp. 21-29, vol. 16, Boston, 1982.

[31] P.Sabella, "A rendering algorithm for visualizing 3D scalar fields", Computer Graphics, pp. 51-58, vol. 22, Atlanta, 1988.

[32] A.Watt \& M.Watt. “Advanced Animation and Rendering Techniques: Theory and Practice”, Addison-Wesley, Reading, Massachusetts, 1992.

[33] M.Levoy, “A Hybrid Ray Tracer for Rendering Polygon and Volume Data”, IEEE Computer Graphics and Applications, pp. 33-40, 1990. 
[34] J.T.Kajiya, \& BP.V.Herzen, "Ray Tracing Volume Densities, Computer Graphics”, vol.18, pp. 165-174, Minneapolis, 1984.

Fourier.eng.hmc.edu,

2017.

[Online].

Available:

http://fourier.eng.hmc.edu/e161/lectures/IP_steps.gif. [Accessed: 14- Nov- 2017].

[36] I.P.Skirnevskiy, A.V.Pustovit, \& M.O.Abdrashitova, "Digital Image Processing Using Parallel Computing Based on CUDA Technology ", Iopscience.iop.org, 2017. [Online]. Available: http://iopscience.iop.org/article/10.1088/1742-6596/803/1/012152/pdf. [Accessed: 14- Nov2017].

[37] "RGB to grayscale conversion in CUDA and OpenCV - Robotic Vision | Machine Learning | Software Development", Robotic Vision | Machine Learning | Software Development, 2017. [Online]. Available: http://www.coldvision.io/2015/11/17/rgb-grayscale-conversion-cudaopencv/. [Accessed: 14- Nov-2017].

[38] P.Skirmevsliy. "Digital Image Processing Using Parallel Computing Based on CUDA Technology", Citeseerx.ist.psu.edu, 2017. [Online]. Available: http://citeseerx.ist.psu.edu/viewdoc/download?doi=10.1.1.259.1845\&rep=rep1\&type=pdf. [Accessed: 23- Sep- 2017].

[39] B.R.Mohapatra, A.Mishra \& S.K.Rout, “A Comprehensive Review on Image Restoration Techniques”, International Journal of Research in Advent Technology, vol. 2, no. 3, 2014.

[40] E.A.Rosas ."Anatomy, Physiology and Biology of Coronary Arteries", Nucleus.iaea.org, 2017. [Online].

Available:

https://nucleus.iaea.org/HHW/NuclearMedicine/IMIC_2013/Presentations/2013-10-

01_Tuesday/AM/A/S4_AlexandersonRosas.pdf. [Accessed: 11- Nov- 2017].

[41] R.Yogamangalam \& B.K.Kartthikeyan. " Segmentation Techniques Comparison in Image Processing ", Citeseerx.ist.psu.edu, 2017. [Online]. Available: http://citeseerx.ist.psu.edu/viewdoc/download?doi=10.1.1.412.1479\&rep=rep1\&type $=$ pdf.

[Accessed: 05- Aug- 2017].

[42] T.Limberg, "Osirix as a Resource", University of Illinois, 2008. 